Reet Pius

\title{
FAMILIENKAPELLEN AUF DEM KIRCHHOF UND DEM GUTSHOFFRIEDHOF
}

In der 1965 erschienenen Geschichte der estnischen Architektur bemerkt Helmi Üprus: „Architektonische, kleine Formen, Grabkapellen und Monumente verbreiteten sich auch in den einsamsten und abgelegensten Winkeln auf dem Lande und bereicherten das allgemeine Bild der Architektur unseres Landes. ${ }^{\prime 1}$

Auf dem Ratshof-Friedhof (Raadi kalmistu) in Dorpat (Tartu) wurde im Jahr 2016 die Familienkapelle des Dorpater Ratsherren Jacob Friedrich Teller restauriert, die nun mit ihrem stolzen Dach aus Kupferblech in großem Kontrast zum sie umgebenen Friedhof der Johannes-Gemeinde steht, bei der sämtliche Gräber unter einem dichten Rasenteppich liegen und von deren Vorhandensein nur einzelne Kreuze und bemooste Steine Kunde geben. Im Verlauf des letzten halben Jahrhunderts sind wohl noch mehrere, in der "Geschichte der estnischen Architektur" behandelten Grabkapellen völlig verfallen, doch im 21. Jahrhundert gibt es örtliche Gemeinden, welche diese wieder in Ordnung bringen.

Grabkapellen sind intime Mahnmale der Familie und wenn ein Geschlecht verschwindet, nagt an ihnen der Zahn der Zeit (Abb. 1). In Estland waren die Familienfriedhöfe verknüpft mit der Kultur

DOI: https://doi.org/10.12697/BJAH.2017.13.07

Übersetzung aus dem Estnischen von Marju und Olaf Mertelsmann.

1 Eesti arhitektuuri ajalugu, hrsg. von Harald Arman (Tallinn: Eesti Raamat, 1965), 268. 


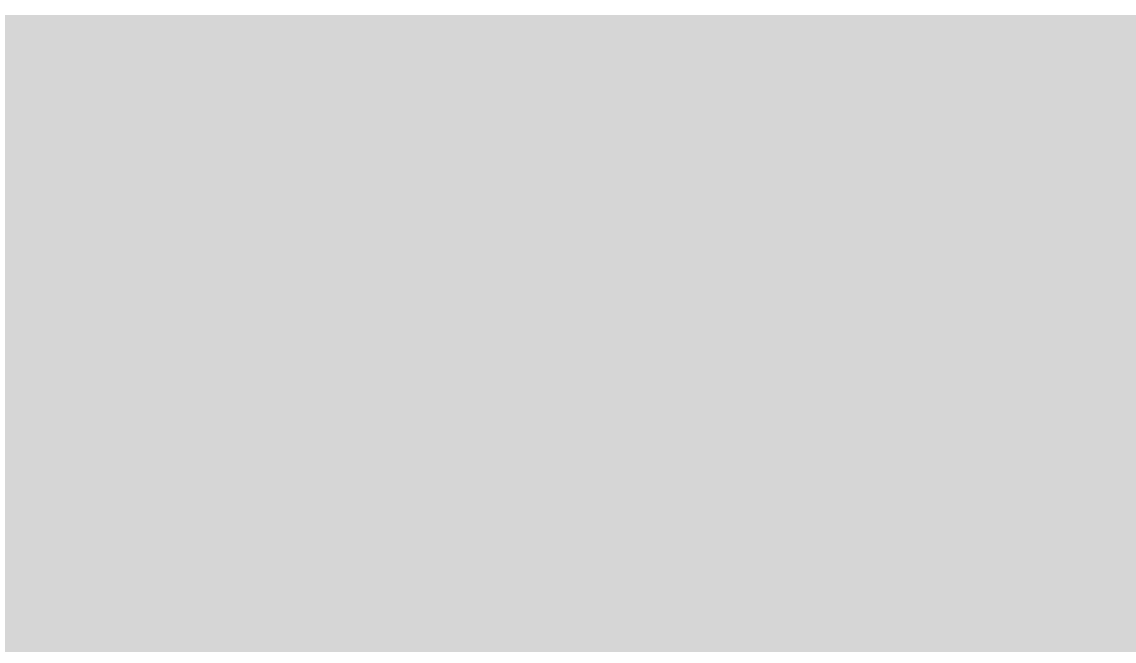

Abb. 1. Grabstein der Gräfin Josephine von Anrep-Elmt (1836-1838) auf Gut Kerstenhof (Kärstna). Foto: Juhan Maiste.

der hier dominierenden deutschbaltischen Gutsherren. Mit dem Landgesetz der Republik Estland von 1919, einer radikalen Landreform, wurde der Grundbesitz der Gutsherren zum größten Teil enteignet und die Hauptgebäude der Güter wurden oftmals in öffentlichem Interesse genutzt. Dort wurden hauptsächlich Schulen eingerichtet, für die Begräbniskapellen nutzlose Gebäude darstellten. Die Friedhöfe der Güter verblieben der Familie, doch die Verbindung der aus Estland Ausgewanderten mit der alten Heimat wurde schwächer und die Ruhestätten der Familie blieben ohne Pflege. Im Rahmen der Umsiedlung und Nachumsiedlung 1939-1941 verließen die Deutschbalten endgültig das Land und niemand kümmerte sich mehr um die letzten Ruhestätten dieser Volksgruppe. Nach dem Zweiten Weltkrieg zerstörte die Sowjetunion alle Kennzeichen der estnischen Eigenstaatlichkeit, doch angegriffen wurden auch andere Merkmale der Vergangenheit, darunter die Begräbnisstätten der deutschen Gemeinden - der barbarischste Akt war die Auflösung der Friedhöfe Ziegelskoppel (Kopli) und Moik (Mõigu) in Reval (Tallinn).

Die Errichtung von Familienkapellen nahm in Estland in den sechziger Jahren des 18. Jahrhunderts ihren Anfang und nach einigen Angaben wurde die letzte auf dem Friedhof im Park von
Gut Neuenhof-Kosch (Kose-Uuemõisa) im Jahr 1905 gebaut. ${ }^{2}$ Bei der Einrichtung von privaten Kapellen deutschbaltischer Gutsherren werden zwei Wellen festgestellt. Die erste erfolgte von den sechziger Jahren des 18. Jahrhunderts bis zu den vierziger Jahren des 19 Jahrhunderts und die zweite Welle seit den achtziger Jahren des 19 Jahrhunderts, als in den Gutshofparks neogotische Kapellen errichte wurden, getragen von der romantischen Theatralität des fin de siècle.

Der vorliegende Beitrag behandelt die erste Welle, die auch als eine Hochzeit des Baus von Begräbniskapellen angesehen werden kann. Der Anfang dieser Welle war verbunden mit einer Reform der aufgeklärten Zarin Katharina II., mit der die Bestattung innerhalb der Kirche und auf dem Kirchhof verboten wurde. Die Reform galt allgemein und berührte sämtliche Schichten der Bevölkerung. Es entstanden drei Typen von Friedhöfen. Erstens wurden in fast allen Kirchspielen 1773-1774 gesondert liegende Friedhöfe eingerichtet. Die Begräbnisstätte der überwiegenden Mehrheit der Gutsherren war auf dem Kirchspielfriedhof. Die herrschende Schich wünschte sich dennoch, sich auf dem Kirchspielfriedhof von der bäuerlichen Bevölkerung abzutrennen und dies führte zum Bau vom Familienkapellen.

Zweitens war das estnische Gebiet territorial aufgeteilt in die Gouvernements Estland, das heutige Nordestland, und Livland, das Südestland und Nordlettland umfasste. Die unterschiedliche Beziehung der Ritterschaften zur Regierung drückte sich sehr stark in den Begräbnisstätten des Adels aus, die Friedhöfe des Adels in der Provinz Estland lagen neben der mittelalterlichen Kirchspielkirche, in Livland war dies nicht erlaubt.

Drittens war im 18. Jahrhundert das Gut nicht bloß eine wirtschaftliche Einheit, sondern auch das Heim eines Großgrundbesitzers, welches in Übereinstimmung mit dem Geschmack der Zeit gestaltet wurde. Im Erholungsbereich des Gutshofs wurde auch die letzte Ruhestätte des Eigentümers eingerichtet - der Gutshoffriedhof. Die Kapelle war ein Teil des Ensembles des Guts und hier zeigte sich die Kreativität des Eigentümers auf leidenschaftliche Weise. 
Diese drei Faktoren haben die Friedhofskultur des Adels geformt und sie lieferten auch weitere Einflüsse. Nach dem Vorbild der Gutsfriedhöfe begannen auch freie estnische Bauern auf ihren Höfen Friedhöfe anzulegen. ${ }^{3}$

In dieser Zeit war die überwiegende Mehrheit der Deutschbalten evangelisch-lutherisch und der Tod war sowohl institutionell als auch rituell mit dieser Religion verbunden. Gleichzeitig hatte der Rektor der Kaiserlichen Universität zu Dorpat, Johann Philipp Gustav von Ewers, die Auffassung verkündet, die christliche Kirche und ihre Rituale seien notwendig für die einfachen Menschen. ${ }^{4}$ Dieser Standpunkt spiegelt auch die allgemeinen Einstellungen der damaligen deutschbaltischen Intellektuellen wider. In der Architektur der Grabkapellen, unabhängig von ihrem Standort, dominierten griechische und römische Vorbilder aus der Zeit vor Jesu Christi (Abb. 2, 13).

Das Zeitalter der Aufklärung richtete den Fokus auf große Geister und Helden, dies lieferte seinerseits den Anstoß zur Diversifizierung der Memorialkunst. In einer pantheistischen Sicht der Welt verfügte die Rettung der Seele nicht mehr über ihre bisherige Bedeutung, die Verklärung erfolgte durch die Bewunderung der großen Geister.

James Stevens Curl verschafft uns eine monumentale Übersicht über die Herausbildung der westeuropäischen Todeskultur und Gedenktradition. ${ }^{5}$ Er beschäftigt sich hauptsächlich mit Formproblemen und davon ausgehend analysiert er das Auftreten neuer Erscheinungen in der materiellen Kultur, die mit dem Tod einhergeht.

Am gründlichsten schreibt Richard A. Etlin über die Prozesse der Herausbildung eines neuen Typs der Friedhofskultur und des Anteils französischer Architekten des Aufklärungszeitalters bei der Schöpfung der visuellen Semantik. ${ }^{6}$ Der Sammelband von Essays Erika Naginskis über die Skulptur der Aufklärungszeit

31875 richtet Carl Robert Jakobson für Kurgja einen Friedhof seines Hofs ein, in den dreißiger Jahren des 20. Jahrhunderts taten dies die Besitzer einer Reihe von Bauernhöfen ebenso.

4 Lea Leppik, Rektor Ewers (Tartu: Eesti Ajalooarhiiv, 2001), 146.

5 James Stevens Curl, Death and architecture: an introduction to funerary and commemorative buildings in the Western European tradition, with some consideration of their settings (Stroud: Sutton Publishing, 2002)

6 Richard A. Etlin, Symbolic Space: French Enlightenment Architecture and Its Legac (Chicago, London: The University of Chicago Press, 1994).

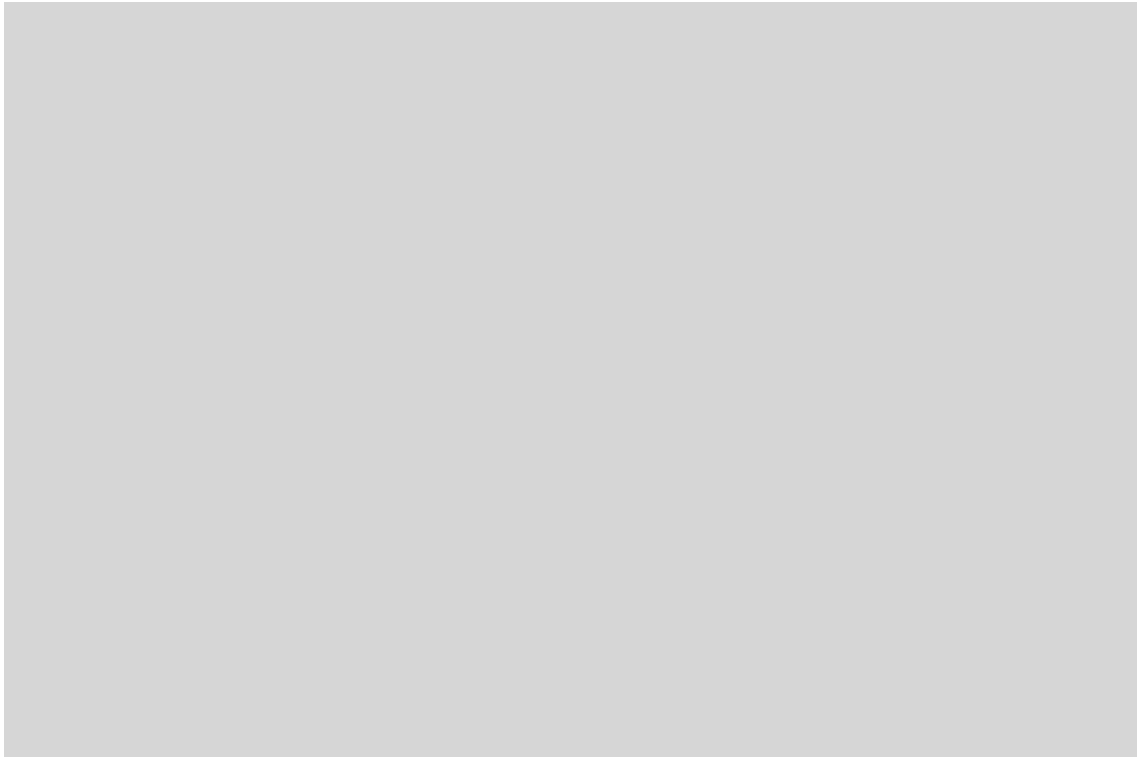

Abb. 2. Die Familienkapelle der von Buxhoevedens beim Tor des Friedhofs von Kudjapäh (Kudjape). 1845-1848. Foto: Juhan Maiste.

widmet sich der Erinnerung von großen Geistern und Helden in der Gedächtniskultur und behandelt die Monumentenkunst als einheitliche Ganzheit, die von der Landschaft, dem architektonischen Denkmal und der Skulptur gebildet wird.?

Unter den estnischen Autoren hat Kadi Polli den Friedhof der Aufklärungszeit als Problematik der künstlerischen Aufgabe behandelt. $^{8}$ Sie analysiert Estlands erstes Handbuch zum Stadtfriedhof ${ }^{9}$ aus der Feder des Pastors der Elisabeth-Kirche in Pernau (Pärnu), Johann Heinrich Rosenplänter, das im Jahr 1823 erschienen ist, und den Beitrag des herausragenden Architekten Johann Wilhelm Krause dabei. Über Krauses Suche nach einem Stil und seine Rolle als Filter für europäische architektonische Ideen

7 Erika Naginski, Sculpture and Enlightenment (Los Angeles, California: Getty Research Institute; Hove: Roundhouse, 2009).

8 Kadi Polli, „Sentiment ja ratio. Hauamonumendid“, Johann Wilhelm Krause 1757-1828. 2, Arhitektina Liivimaal, hrsg. von Juhan Maiste, Kadi Polli, Mariann Raisma (Tallinn: Eest Keele Sihtasutus, 2002), 269-300.

9 Johann Heinrich Rosenplänter, Ueber Kirchhöfe und Beerdigung der Todten, nebst einem Anhange, den Pernauschen Kirchhof betreffend (Pernau: Gotthardt Marquardt, 1823). 
schreibt Juhan Maiste ${ }^{10}$ - beide Aufsätze erschienen im Sammelband „Johann Wilhelm Krause. Arhitektina Liivimaal (Als Architekt in Livland)“.

Eine Übersicht über die Familienfriedhöfe estnischer Gutsherren und ihren momentanen Zustand verschaffen der Geograf Taavi $\mathrm{Pae}^{11}$ und Ketlin Sirge ${ }^{12}$, die über eine theologische Ausbildung verfügt. Beide Arbeiten erheben nicht den Anspruch, eine Bewertung der Kunst zu vergeben, aber es handelt sich um wertvolle Zusammenstellungen von Material. Sie haben mehr als einhundert Gutsfriedhöfe registriert. Die Begräbnisstätten est- und livländischer Familien sind eng verbunden mit der Parkkultur der Gutshöfe, so ist eine Behandlung durch Ants Hein in seiner Überblicksdarstellung „Eesti pargid (Estlands Parks)“ erschienen. ${ }^{13}$

In den dreißiger Jahren des 20. Jahrhunderts hat die deutschbaltische Gemeinschaft Angaben über die Grabstätten ihrer Angehörigen versammelt, die Abschriften der Necropolis umfassen die Zeit vom Ende des 18. Jahrhunderts bis zum Beginn des 20. Jahrhunderts. ${ }^{14}$ Diese Materialien stellen wichtige Quellen zur Untersuchung der Memorialkultur dar, sie machen die Datierung und die Baugeschichte so mancher Kapelle somit exakter.

\section{DIE ENTSTEHUNG DER IDEE DES GARTENFRIEDHOFS}

Bis zur Aufklärung war die Bestattung in der Kirche ein Privileg der höheren Stände. Doch die Kirche stand dafür, dass die einfache Bevölkerung auf dem neben der Kirche eingerichteten Friedhof angemessen bestattet wurde - dem Kirchhof. Die im 13. Jahrhundert christianisierten Esten bevorzugten noch im 17. Jahrhundert, die

10 Juhan Maiste, ,J. W. Krause ja ajastu arhitektuuripilt“", Johann Wilhelm Krause 1757-1828. 2, Arhitektina Liivimaal, hrsg. von Juhan Maiste, Kadi Polli, Mariann Raisma (Tallinn: Eest Keele Sihtasutus, 2002), 23-75.

11 Taavi Pae, Formation of Cultural Traits in Estonia Resulting from Historical Administrative Division. Dissertationes Geographicae Universitatis Tartuensis, 28 (Tartu: Tartu University Press, 2006).

12 Sirge, Eesti mõisakalmistud.

13 Ants Hein, „Aed ja aeg. Piirjooni eesti aiakunsti vanemast ajaloost“, Eesti pargid 1 (Tallinn: Keskkonnaministeerium, Muinsuskaitseamet, Varrak, 2007), 15-87.

14 Estnisches Historisches Archiv [Ajalooarhiiv, EAA], 1674-2-333-339; 1674-2-765. (Necropolis von Estland.)
Verschiedenen auf einem Waldfriedhof zu begraben, und bereiteten damit der Regierung Kopfschmerzen.

Anders war das Leben in den europäischen Großstädten. London und Paris verfügten im 18. Jahrhundert über ungefähr 600.000 Einwohner und waren damit die größten Städte der Welt. Der große Brand 1666 in London verursachte hygienische Probleme, weshalb der Schriftsteller und Gärtner John Evelyn und der Architekt Christopher Wren empfahlen, einen großangelegten Friedhof außerhalb der Stadt einzurichten und für dessen Planung, die besten Architekten zu berufen. ${ }^{15}$ Dieser Schritt bedeutete, der anglikanischen Kirche entgegenzutreten, welche, um die Kontrolle über die "Seelen“ zu behalten, auch eine Bestattung auf dem Kirchhof forderte. Evelyns und Wrens Idee im Sinne der Planung wurde nicht umgesetzt.

Das 18. Jahrhundert begrub Paris in hygienischen Problemen, die noch umfangreicher waren als in England. Auf dem Friedhof der Unschuldigen (Cimetière des Innocents) wurden die Leichen in riesigen Massengräbern bestattet, die erst geschlossen wurden, wenn sie gefüllt waren. Besser war die Situation auch in den Kirchen nicht, in denen der Gestank zerfallender Körper erstickend war, und die Trinkwasserquellen wurden verschmutzt. 1737 begann die Pariser Stadtverwaltung die Situation zu untersuchen und im Jahr 1763 wurde die Entscheidung gefällt, Begräbnisstätten außerhalb der Stadtgrenzen anzulegen, wie dies im alten Rom der Fall gewesen war. ${ }^{16}$ Erst die Überschwemmung des Jahres 1779, deren überlaufendes Wasser Wohnungen und Keller verschmutzte, führte ein Jahr später zur tatsächlichen Schließung des Friedhofs der Unschuldigen. ${ }^{17}$

Als das Problem auftrat, begann die Académie royale d'architecture das Problem „mit einem dem Aufklärungszeitalter eigenen Selbstbewusstsein" zu lösen, und organisierte 1765 einen studentischen Architekturwettbewerb, um eine Lösung in Form

15 Curl, Death and architecture, 136. Evelyns und Wrens Idee von einem Friedhofspark setzte sich eher von selbst um, als die bei der anglikanischen Kirche bestehenden Glaubensströmungen sich von ihr losten und de Fiedhor Bunhill iselds einichteten, der von den sechziger Jahre des 17. Jahrhunderts bis 1855 als Friedhof für die Nonkonformisten genutzt wurde.

16 Ira Diana Mazzoni, Aiad ja pargid. Aiakunst antiigist tänapäevani (Tallinn: TEA Kirjastus, 2006), 190-191.

17 Cimetière des Innocents (Friedhof der Unschuldigen): http://cultureandstuff.com/2011/06/08 lost-paris-the-cimetiere-des-innocents/ [letzter Zugriff am 30.07.2017] 
einer Nekropole zu erhalten. ${ }^{18}$ Der Geist der Zeit forderte anstelle von spontan um Kirchen herum entstandenen Begräbnisstätten eine von einem Architekten geplante Stadt der Toten, die den Erwartungen der Gegenwart an Sauberkeit, Ordnung und frischer Luft entsprachen und außerdem noch den Menschen eine angenehme Umgebung für Spaziergänge und zum Nachdenken bieten sollte.

Für einen Durchbruch wird der Wettbewerb Grand Prix de Rome ${ }^{19}$ des Jahres 1785 gehalten. Pierre Fontaines Entwurf für einen Pariser Friedhof erhielt den zweiten Preis und darin erkennbar war die Überlegenheit der Natur, obwohl die Hauptelemente dieses Entwurfs eine zentrale, durch eine Kolonnade begrenzte Pyramide und kleine Pyramiden in den Ecken eines quadratischen Säulengangs waren. ${ }^{20}$ Die Stimmung der Überlegenheit der Natur verschaffen auf der Zeichnung die am Ort der Nekropole sich auftürmenden dramatischen Wolken. Ägyptische Pyramiden waren als Todessymbol im Zeitalter der Aufklärung unter französischen Architekten eine hauptsächliche Figur, über kolossale Ausmaße verfügt diese in den megalomanischen Nekropolenentwürfen von Étienne-Louis Boulée. ${ }^{21}$

Bereits der französische Theologe und Architekturtheoretiker Marc-Antoine Laugier hatte in der Pyramide dialektische Symbole von Himmel und Erde gesehen: die massive Grundfläche der Pyramide verjüngt sich zum Himmel hin zu einem Punkt. So kann man sich auch das Verlassen der Seele aus dem Körper für die Ewigkeit vorstellen. ${ }^{22}$

Als einflussreichster künstlerischer Export des 18. Jahrhunderts gilt der englische Landschaftspark. ${ }^{23}$ Dessen natürlichen Rahmen füllten französische Architekten und Philosophen mit einem erhabenen und vornehmen Inhalt. Zum Apologeten des Landschaftsparks in

18 Naginski, Sculpture and Enlightenment, 49.

19 Der Grand Prix de Rome war ein von der Regierung Ludwigs XIV. begründetes staatliches tstudenten, deren zwei Gewinner sich für drei bis fünf Jahre in Ron fortbilden konnten

20 Etlin, Symbolic Space, 152

21 Ibidem, 20. In Estland war eine durch Ägypten beeinflusste Formsprache im 18. Jahrhundert nicht annehmbar, ein Beispiel für eine Ausnahme ist die Kapelle des Gutsherrens von Kurrista Kurista) und Sarrakus (Sarakuste), Alexander Guillemot de Villebois (1717-1781), auf dem Friedhof von Wenno (Võnnu)

22 Marc-Antoine Laugier, Observations sur l'Architecture (La Haye, Paris: Chez Desaint, Libraire, 1765), 241

23 Curl, Death and architecture, 253
Frankreich wurde Jean-Jacques Rousseau, dessen ausgesprochen sentimentaler Roman "Julie oder die neue Héloïse“ zahlreiche Naturbeschreibungen enthielt, welche der Verfasser auf seiner Reise nach England erfahren hatte. Das Buch erreichte eine große Popularität und lieferte unter anderem auch den Impuls zur Anlage von natürlichen Parks auf dem europäischen Festland. Rousseau verstarb 1778 auf dem nahe von Paris gelegenen Landgut Ermenoville seines Freunds, des Marquis René-Louis de Girardin, und er wurde dort in einem Pappelhain auf einer Insel namens Île des Peupliers inmitten eines Sees beigesetzt. Rousseaus Grab wurde zu einem kultischen Ziel für gebildete Europäer ${ }^{24}$, dieses wurde auf Stichen dargestellt und davon wurden Kopien angefertigt. Die bekannteste von ihnen befindet sich in Wörlitz in Deutschland, doch es wurde auch auf dem Gut Drostenhof (lettisch Drusti) in Livland und dem Gut Mödders (Mõdriku) in Estland nachgeahmt. ${ }^{25}$

Auf dem Boden der brutalen Massenexekutionen und der Massengräber der 1789 ausgebrochenen Französischen Revolution entsprang der Gedanke des Werts des Lebens. Gleichzeitig säte die Revolution Furcht, der Tod wurde nicht länger als Tod bezeichnet, den Friedhof nannte man Elysium (Elysée) oder "Ruhestätte“ (lieu de repos). ${ }^{26}$

Als das Verbot der Bestattung in der Kirche in Frankreich schließlich am 12. Juni 1804 zum Gesetz wurde, forderte man für jeden Menschen seinen Grabplatz und wenigstens fünf Jahre Grabesruhe. ${ }^{27}$ Paris erhielt seinen Friedhof am Stadtrand - Père Lachaise. Aus einem verwilderten Barockgarten wurde ein stimmungsvoller Landschaftspark gestaltet.

24 The History of Garden Design. The Western Tradition from Renaissance to the Present Day, hrsg. von Monique Mosser, Georges Teyssot (London: Thames and Hudson, 1991), $337-$ 338. html [letzter Zugriff 30.07 .2017 .

25 Ilze Māra Janelis, Manor gardens and parks of Latvia (Riga: Neputns, 2010); Juhan Maiste, „Balti mõisapanteon“, Eesti kunsti ajalugu 1770-1840, 3, hrsg. von Juhan Maiste (Tallinn: Eesti Kunstiakadeemia, 2017), 277.

26 Etlin, Symbolic Space, 163

27 In den lutherischen Ländern, darunter auch in Estland, sah das bis 1832 geltende Kirchengesetz vor, Tote schnellstens zu beerdigen und (mit Erde) zu bedecken, siehe Merike Kurisoo, Ars moriendi - suremise kunst: näitus Niguliste munseumis 02.11.2012-02.06.2013 (Tallinn: Eesti Kunstimuuseum 2013), 66. 


\section{DIE KRAFT DES GESETZES IN RUSSLAND}

Die russische Zarin Katharina II. erhielt wahrscheinlich den Anstoß zur Umorganisierung der Friedhöfe durch den Briefwechsel mit dem französischen Philosophen François Voltaire. ${ }^{28}$ Per Ukas der Zarin vom Jahr 1772 wurde in Russland die Bestattung in Kirchen und auf Kirchhöfen verboten. Aus hygienischen Erwägungen mussten sich die Friedhöfe in wenigstens 300 Sažen' (Klafter) oder etwa 600 m Entfernung von Wohngebäuden befinden. ${ }^{29}$ In den Gouvernements Est- und Livland wurden auf Grundlage des Ukasses Erlasse, welche die Friedhöfe betrafen, im frühen Frühjahr 1773 ausgegeben. Damit hatte die Einstellung der Aufklärungszeit in der Todeskultur in Russland Gesetzeskraft erhalten, wohin man in Frankreich erst mehr als dreißig später gelangte.

\section{KIRCHHÖFE NEBEN DER KIRCHE}

Dennoch entwickelte sich nicht alles ohne Behinderungen. Die deutschbaltischen Adligen, die über ständische Privilegien verfügten, wollten nicht so einfach nachgeben. Wegen des intensiven Widerstands estländischer Adliger gelang es ihnen, das Gesetz nachsichtiger interpretieren zu lassen, und im Erlass wurde ihnen die Beerdigung auf dem Kirchhof erlaubt, also neben der Kirchspielkirche. In den Städten erreichten sie dies natürlich nicht und die deutschen Gemeinden in Reval legten ihre Friedhöfe in Ziegelskoppel und Moik an (Abb. 3) Die Grabkammern in den Kirchen waren zuzumauern, doch die Familien durften auf Wunsch ihre verstorbenen Angehörigen umbetten. ${ }^{30}$

28 Als Ergebnis eines Dekrets der Pariser Stadtverwaltung aus dem Jahr 1765 wurde das Erlangen einer visuellen Lösung der neuen Friedhöfe den Studenten der Académie royale d'architecture zur Aufgabe gemacht. Louis Jean Desprez, der den Wettbewerb der Akademie gewonnen hatte, widmete seine Arbeit später Voltaire. Siehe: Naginski, Sculpture and Enlightenment, 49-50. Der schwedische König Gustav III. nahm Desprez dann in seine Dienste uf. Die von ihm entworfene Kirche von Tavastehus (finnisch Hâmeenlinna) von 1798, die den römischen Pantheon folgt, hat Spuren in der Rezeption der Antike in Finnland hinterlassen.

29 Полное собрание законов Российской Империи I, том XIX, 1770-1774, №13927 (Санктпетербург: Типография II Отделения Собственной Его Императорского Величества Канцелярии, 1830), 691.

30 Pae, Formation of cultural traits in Estonia, 26. Die Umbettung erschwert auf den

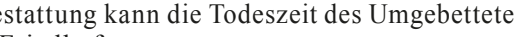
edeuten und nicht den Zeitpunkt der Anlage des Friedhofs.

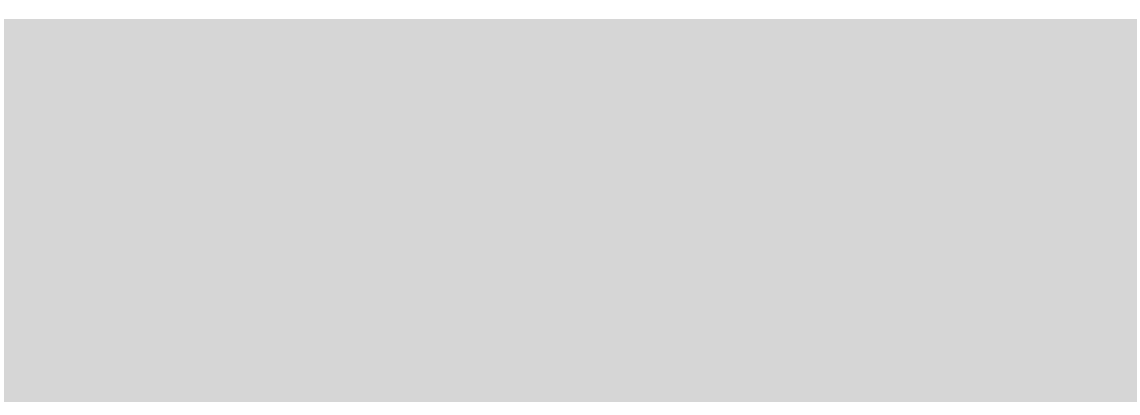

Abb. 3. Carl Friedrich Wilhelm Buddeus. Kirchhof in Moik (Mõigu) an der Dorpater Straße. 1836. Estnisches Historisches Museum.

Der Altarraum wurde für den prestigeträchtigsten Bestattungsort gehalten und es wurde vorgezogen, Familienkapellen in unmittelbare Nähe des Chorraums zu bauen oder in den sonnigeren Süd- und Westflügeln der Kirche. Ein Grabplatz neben der Kirche blieb dennoch nur ein Privileg für die deutschbaltischen Adligen und für den deutschen Pfarrer der Gemeinde. Für die bäuerliche Bevölkerung und die einfacheren Deutschen wurde ein Friedhof in weiterer Entfernung von der Siedlung eingerichtet.

Im Gouvernement Livland, wo die Umsetzung des Erlasses von Offizieren überwacht wurde, durften keine Grabkapellen neben den Kirchen erbaut werden. Deshalb ist die größere Anzahl an Gutshoffriedhöfen in den Kreisen Fellin (Viljandimaa) und Werro (Võrumaa) in Livland eher ein Beleg für die Steifheit der Beziehungen zwischen den Ständen als für eine Offenheit für die neue Idee des Friedhofparks. Doch gleichzeitig muss bemerkt werken, dass die dortige stimmungsvolle und leicht hügelige Landschaft sicherlich inspirierend war.

\section{KIRCHSPIELFRIEDHÖFE (KIRCHHOF - FRIEDHOF)}

Der Kirchhof stellte sowohl einen Kirchhof im direkten Sinne des Wortes dar als auch einen Kirchspielfriedhof, der entfernt von der Kirche angelegt wurde. Ein auf einem Feld angelegter Friedhof wird mancherorts auch als Gottesacker bezeichnet, ${ }^{31}$ eigentlich eine

31 EAA, 1216-1-134, 5. Gottesacker erscheint auch auf Karten vom Anfang des 19. Jahrhundert diese Bezeichnung müsste in den Ostseeprovinzen weit verbreitet gewesen sein, denn sie gelangt
auch ins Deutsch-Estnische Wörterbuch. 


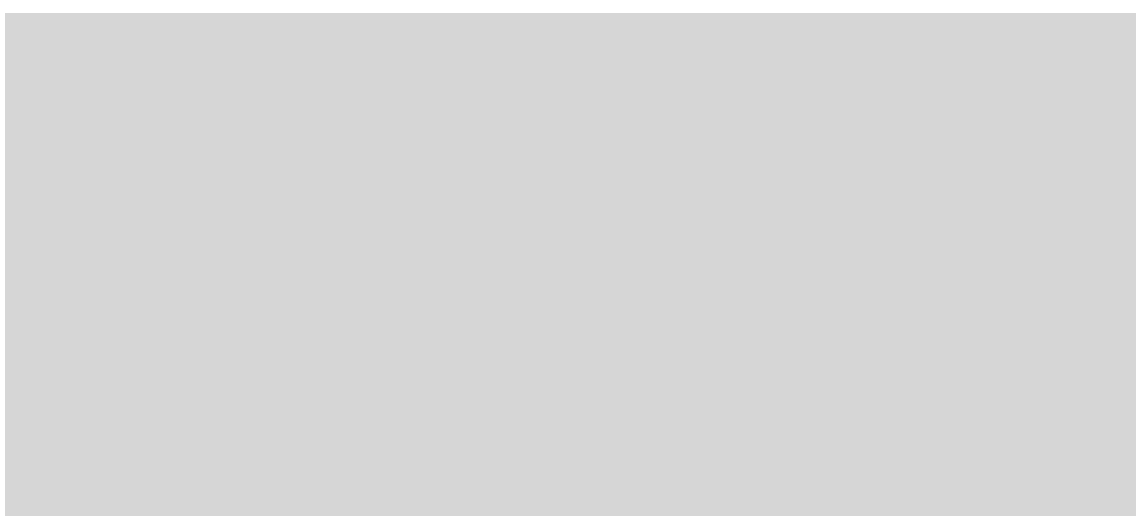

Abb. 4. Karte das Pastorats Kusall (Kuusalu). Auf der Karte ist ein von der Kirche entfern gelegener Friedhof zu erkennen, der als Gottes Acker bezeichnet wurde. Estnisches Historisches Archiv.

veraltete Bezeichnung für Friedhof (Abb. 4). Der Pernauer Pastor und Schriftsteller Johann Heinrich Rosenplänter bietet in seinem 1823 erschienenen Buch zur Friedhofsgestaltung das Synonym Friedhof an und begründet den Vorschlag damit, dass sich der "Kirchhof" oftmals in kilometerweiter Entfernung von der Kirche befinde. ${ }^{32}$

Über den Friedhof in Fischermai (Kalamaja) in Reval stammen Nachrichten schon aus dem 16. Jahrhundert, doch Fischermai war eine eigenständige Vorstadt und der Friedhof einer Siedlung kann nicht als eine Begräbnisstätte außerhalb der Stadt angesehen werden. Erst nach der Reform Katharinas II. wurde die Einrichtung von Kirchspielfriedhöfen zu einer allgemeinen Erscheinung. Per Gesetz wurden die Kirchenvorsteher verpflichtet, sich um die Begräbnisstätte der Gemeinde zu sorgen. Dabei handelte es sich zumeist um einen örtlichen Gutsherren, der Land zur Verfügung stellte, dieses einzäunen ließ und einen Weg anlegte. ${ }^{33}$ So gestalteten sich die Gottesäcker nach der Umsicht und den Ansichten des Kirchenvorstehers. Und wenn diese große Unternehmung umgesetzt und dafür geeignetes Land gefunden wurde, dann legte der Gutsherr dort auch seine Grabstätte an. Die Kapelle des Herren verlieh dem Friedhof einen Akzent und eine Orientierung, sie befand sich an

32 Rosenplänter, Ueber Kirchhöfe und Beerdigung der Todten, 7

33 August Wilhelm Hupel, Topographische Nachrichten von Lief- und Ehstland, 2 (Riga: Johann Friedrich Hartknoch, 1777), 84-85.

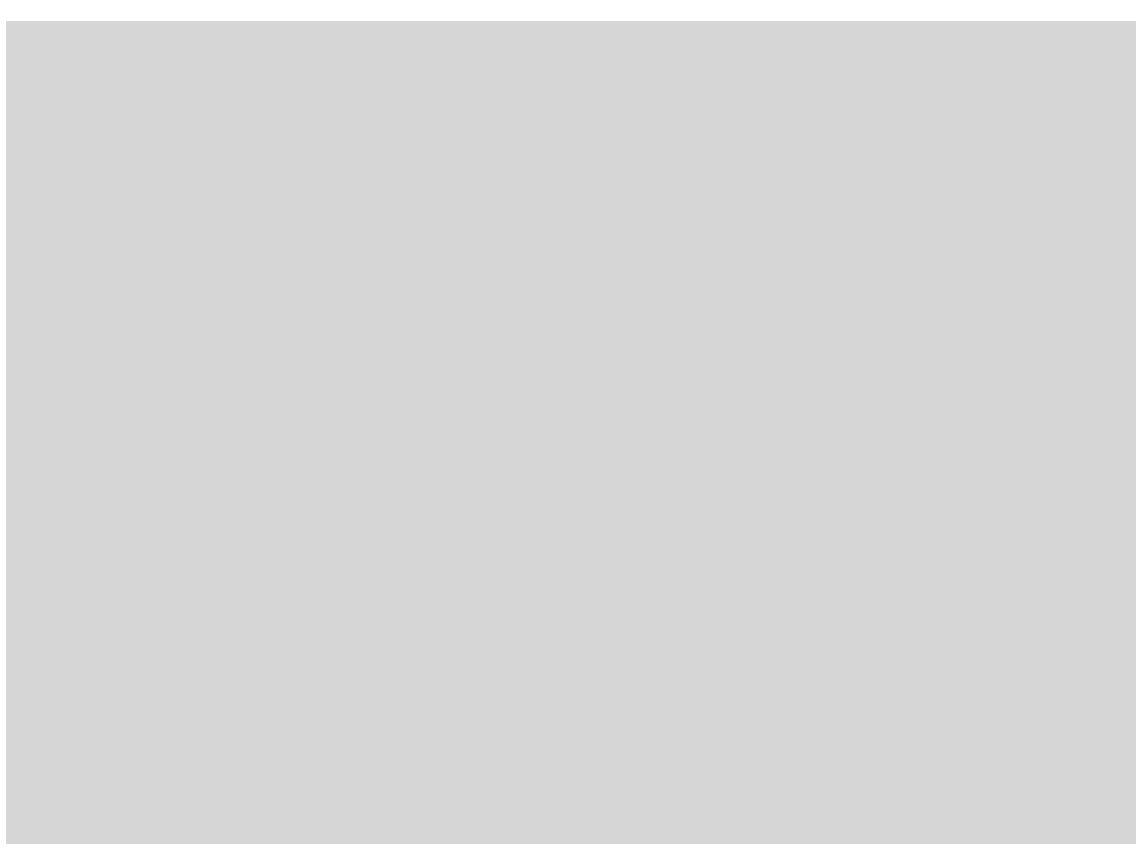

Abb. 5. Johann Schultz. Lageplan der Kapellen des Friedhofs Ziegelskoppel (Kopli). 1774. Stadtarchiv Tallinn

einem auffälligen Ort neben dem Friedhofseingang oder am Ende des mittleren Wegs.

Einen Friedhof als Umwelt zu schaffen mit ihren sicheren ästhetischen und ethischen Ansprüchen, war eine neue Aufgabe. Den ersten bekannten Friedhofsplan legte der estländische Gouvernementsarchitekt Johann Schultz im Jahr 1774 an für den Friedhof Ziegelskoppel der Gemeinden der Olai- und der Nikolaikirche (Oleviste und Niguliste) an (Abb. 5). ${ }^{34}$ Auf dem Lageplan der Kapellen von Schultz befinden sich diese eng nebeneinander um einen rechteckigen Platz herum, dessen eine Seite freigelassen wurde Diese Lösung erinnert an die Kreuzgänge mittelalterlicher Kirchen. Im 1626 erschienenen Buch Architectura Civilis von Joseph Furttenbach war der lutherische Friedhof noch eine geschlossene Klausur ${ }^{35}$ und bessere Vorbilder waren noch nirgends $\mathrm{zu}$ finden. Neben dem Lageplan entwarf Schultz in Ziegelskoppel auch Kapellen, deren

34 Tallinner Stadtarchiv [Tallinna Linnaarhiiv, TLA], 149-4-406, 24

35 Joseph Furttenbach, Architectura civilis (Tafeln) (Ulm, 1628), T 40. 
architektonisches Aussehen sich nicht von dem an die Kirchenmauer Angebauten unterschied. Dafür ist die Kapelle der von Clodts in der Revaler Nikolaikirche ein Beispiel, wahrscheinlich ebenfalls Schultzes Schöpfung.

\section{MAUSOLEUM ODER GRABKAPELLE}

Das Mausoleum hat seinen Namen im 4. Jahrhundert vor Christi nach dem in Halikarnassos (heute Bodrum in der Türkei) herrschenden persischen Satrapen Mausolos erhalten. Das Mausoleum wurde zur allgemeinen Bezeichnung einer Grabkapelle, doch in Estland wird einzig die Grabkapelle von Generalfeldmarschall Fürst Michael Andreas Barclay de Tolly auf Gut Beckhof (Jõgeveste) als Mausoleum bezeichnet. Damit wird die ins Auge stechende Rolle dieses Heerführers in Russlands Kriegen gegen Napoleon betont. ${ }^{36}$

Die Grabkapelle des 18. Jahrhunderts und der ersten Hälfte des 19. Jahrhunderts war zweistöckig mit einem Grabgewölbe im Kellergeschoss und darüber einer Kapelle zur Erinnerung an die Toten. Wenn über dem Grabgewölbe eine Kapelle war, bezeichnete man das Gebäude als eine Kapelle, seltener als eine Grabkapelle. Eine Grabrotunde vermerkte eine runde Kapelle, also eine Rotunde. ${ }^{37}$

Feldmarschall Georg Reinhold von Lieven (1696-1763) forderte in seinem Testament von 1762 die Bestattung auf dem Kirchhof von Karkus (Karksi) in einer ordentlich gewölbten Grabkammer. Er wollte in seiner Kavallerie-Paradeuniform bestattet werden und aus diesem Anlass sollten die Kirchenglocken läuten. ${ }^{38}$ Die Errichtung der Kapelle war ein Monument seitens der Ehefrau von Lievens, Elisabeth, zur Erinnerung an ihren verblichenen Gatten.

Ein Erbbegräbnis konnte sowohl ein Gebäude mit Grabkammer als auch mit Kapelle bedeuten, eine Entsprechung wären sowohl die Familienkapelle als auch der Familienfriedhof. In deutschsprachigen Quellen trifft man dies überwiegend an. Manch eine Kapelle konnte

36 Im Russischen ist eine Grabkapelle ein Mausoleum (маусолеум), da Barclay de Tolly ein russischer Heerführer war, erscheint dies als die wahrscheinlichste Erklärung für den Gebrauch des Begriffs.

37 Rosenplänter, Ueber Kirchhöfe und Beerdigung der Todten, T III.

38 Alexander Lieven, Urkunden und Nachrichten zu einer Familiengeschichte der Barone, Freiherren, Grafen und Fursten Lieven, II (Mitau, 1911), 302. „Das mein erblasster Körper in das bei der Karkuschen Kirche auf dem Kirchofe zu dem ende neu erbaute besondere Gewölb nach dem Namen des einen oder anderen Eigentümers bekannt sein denn Familienkapellen wurden ebenso weiterverkauft, wie dies früher mit den Grabplätzen in der Kirche geschehen war.

\section{QUELLEN DER INSPIRATION}

Als Bibel der Gartenkunst wurde das fünfbändige Werk des Professors der Universität Kiel, Christian Cajus Lorentz Hirchfeld, „Theorie der Gartenkunst" bezeichnet, ${ }^{39}$ es bot mehrere Lösungen für die Einrichtung eines Friedhofs im Wald oder im Park an und im Werk fanden sich Zeichnungen von Pavillons, die als Kapellen geeignet waren. Obwohl Hirschfeld eher ein Zusammensteller war, versammelte er in seinen Büchern die Diskussionen bekannter Denker und seine Publikationen waren sehr populär. Zusätzlich zu Hirschfelds Veröffentlichungen konnte ein Gutsbesitzer Ideen zur Landschaftsgestaltung aus der Gartenzeitschrift „Ideenmagazin für Liebhaber von Gärten“ oder aus dem speziellen Handbuch „Taschenbuch für Garten-Freunde“ entnehmen. ${ }^{40}$ Der örtliche Pastor August Wilhelm Hupel lobte in seinen Veröffentlichungen die Schönheit so manches est- und livländischen Gutshofs. Wahrscheinlich regte dies andere an, diese Vorbilder zu befolgen Dennoch bemerkte Johann Heinrich Rosenplänter noch fast ein halbes Jahrhundert später, dass es an Vorbildern fehle, und dies motivierte den Pastor, der dem Problem ins Auge sah, für andere Pfarrer und Kirchenvorsteher das Handbuch „Ueber Kirchhöfe und Beerdigung der Todten, nebst einem Anhange, den Pernauschen Kirchhof betreffend" zusammenzustellen. Im Buch befinden sich der Plan eines Friedhofsparks und diejenigen für sechs Familienkapellen, von denen einige aus dem Werk Hirschfelds kopiert sind. ${ }^{41}$ In der Publikation werden auch geeignete Lieder für die Beerdigung und Grabinschriften sowohl auf Deutsch als auch auf Estnisch angeführt. Neben den praktischen Handbüchern bereitete die schöne Literatur die Menschen auf einen Meinungswandel vor. ${ }^{42}$

39 Christian Caius Lorentz Hirschfeld, Theorie der Gartenkunst, 1-5 (Leipzig: M. G. Weidmanns Erben und Reich, 1779-1785).

40 Gottlieb Wilhelm Becker, Taschenbuch für Garten-Freunde 1796: Die Gartenkunst oder ein auf vieljährige Erfahrung gegründete Unterricht... (Leipzig: Voss und Compagnie, 1796).

41 Rosenplänter, Ueber Kirchhöfe und Beerdigung der Todten, T III.

42 Etlin, Symbolic Space, 160 
Die Sammlung Idyllen (1756) des schweizer Dichters Salomon Gessner wurde zu einem Kultbuch. Der Inhalt bestand in den pastoralen Reisen eines einfachen Hirten zum Grabe der Geliebten. Gessner verherrlichte das Grab als einen Altar der Familie, an dem die verflossenen Generationen getroffen werden konnten und ihnen Ehrerbietung erwiesen werden konnte (Abb. 6). ${ }^{43}$ Dies stimmte Menschen in ganz Europa darauf ein, die Idee eines Gartenfriedhofs anzunehmen.

In der Begeisterung für die Antike erschienen Neudrucke des Aeneis des römischen Dichters Vergil, ${ }^{44}$ in dessen sechstem Lied der Held Aeneas seinen Weg zum Treffen mit seinem Vater schildert, den er findet am Ufer mit den betäubenden blühenden Lilien des Unterweltflusses Lethe, wo alles endgültig schläft. Von dem durch das Tor in das blühende Elysium Hineingelangten [...] leuchtend bleibt nur der ätherische Geist erhalten, eine Flamme sauberer als Luft und klarer. ${ }^{45}$

Die große Anzahl der Schriften des französischen Geistlichen, Freimaurers und Poeten Jaques Delille (1738-1813) in estnischen Bibliotheken - insgesamt 15 Exemplare, zumeist sehr teure, mit goldverzierten Ledereinbänden - belegen die Liebe unter dem hiesigen Adel für das die pastorale Idylle beschwörende Werk dieses französischen Dichters. Les Jardins Ou L'Art D'Embellir Les Paysages und dessen deutsche Übersetzung Die Gärten. Ein Lehrgedicht in vier Gesängen (1796) waren unter den estländischen Gattinnen der Gutsherren ebenso wichtige Inspirationsquellen wie Handbücher zum Gartenwesen. ${ }^{46}$ „Ein Denkmal für einen Philosophen ist eine Dekoration, das echte Grab schafft echte Gefühle, süße und traurige Erinnerungen“, suggerierte Delille. Grabinschriften im Schatten der Bäume wie „Hier ruht ein guter Vater, ein lieber Sohn, ein geliebter Ehegatte“, lassen das Herz zerspringen voller elegischer Gefühle und halten die Erinnerung

43 Etlin, Symbolic Space, 160.

44 Vergilius Maro, Virgils Aeneis / travestirt von Blumauer.

45 Publius Maro Vergilius, Bucolica. Aeneis (Tallinn: Sihtasutus Hortus Litterarum, 1992), 171,172

46 Orrisaar (Esna), Tarwast (Tarvastu), Karkus und Beckhof können als Beispiele dienen für einige der von der Gattin des Gutsherrens bestellten Familienkapellen.

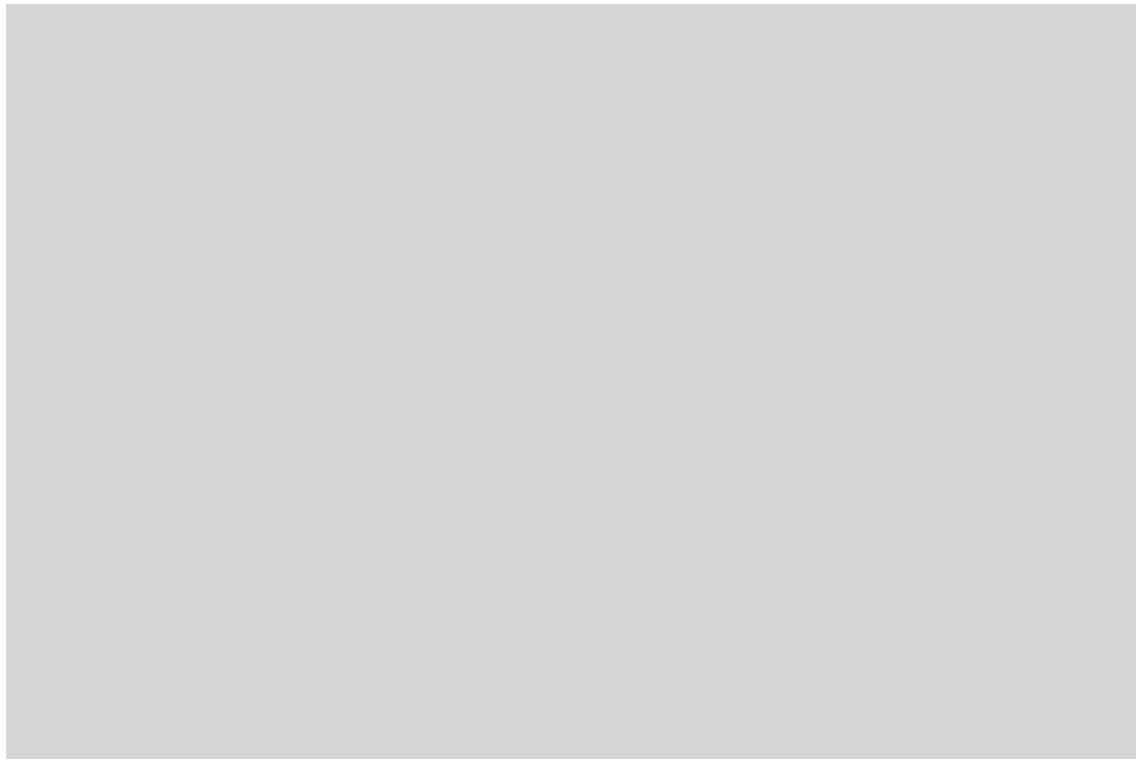

Abb. 6. Das Wappen den von Buxhoevedens auf der Fassade der Familienkapelle. Foto Juhan Maiste.

frisch. ${ }^{47}$ „Der vom Obstbaum gepflückte Apfel erinnert an die gemeinsam verbrachte Zeit, traurige Bäume machen das Herz traurig." Als traurige Bäume bezeichnete man die immergrüne Eibe, Kiefern und Zypressen. In den estnischen Gutshofparks pflanzte man sich an das hiesige Klima anpassende Lebensbäume und Tannen, aber auch örtliche Fichten wurden genutzt. Häufig führte eine Eichenallee zum Friedhof. ${ }^{48}$

\section{GUTSHOFFRIEDHÖFE}

Aus Estland sind 112 Familienfriedhöfe von Gutsherren bekannt, ${ }^{49}$ von denen die Hälfte vor der Mitte des 19. Jahrhunderts angelegt worden sind. Am Beispiel Estlands ist ersichtlich, dass viele Adlige an Traditionen festhielten und als eine letzte Ruhestätte einen Ort in

47 Etlin, Symbolic Space, 161; Jaques Delille, Les Jardins, ou l'Art d'embellir les paysages, poëme (Brunswick: chez Fauche Lt Comp. imprimeurs-libraires, 1801), 85, 100-101.

48 Sirge, Eesti mõisakalmistud, 30.

49 Ibidem. Über die Gutshoffriedhöfe in Harrien und im Kreis Werro sind die Angaben lückenhaft und sie sind nicht exakt datierbar. 


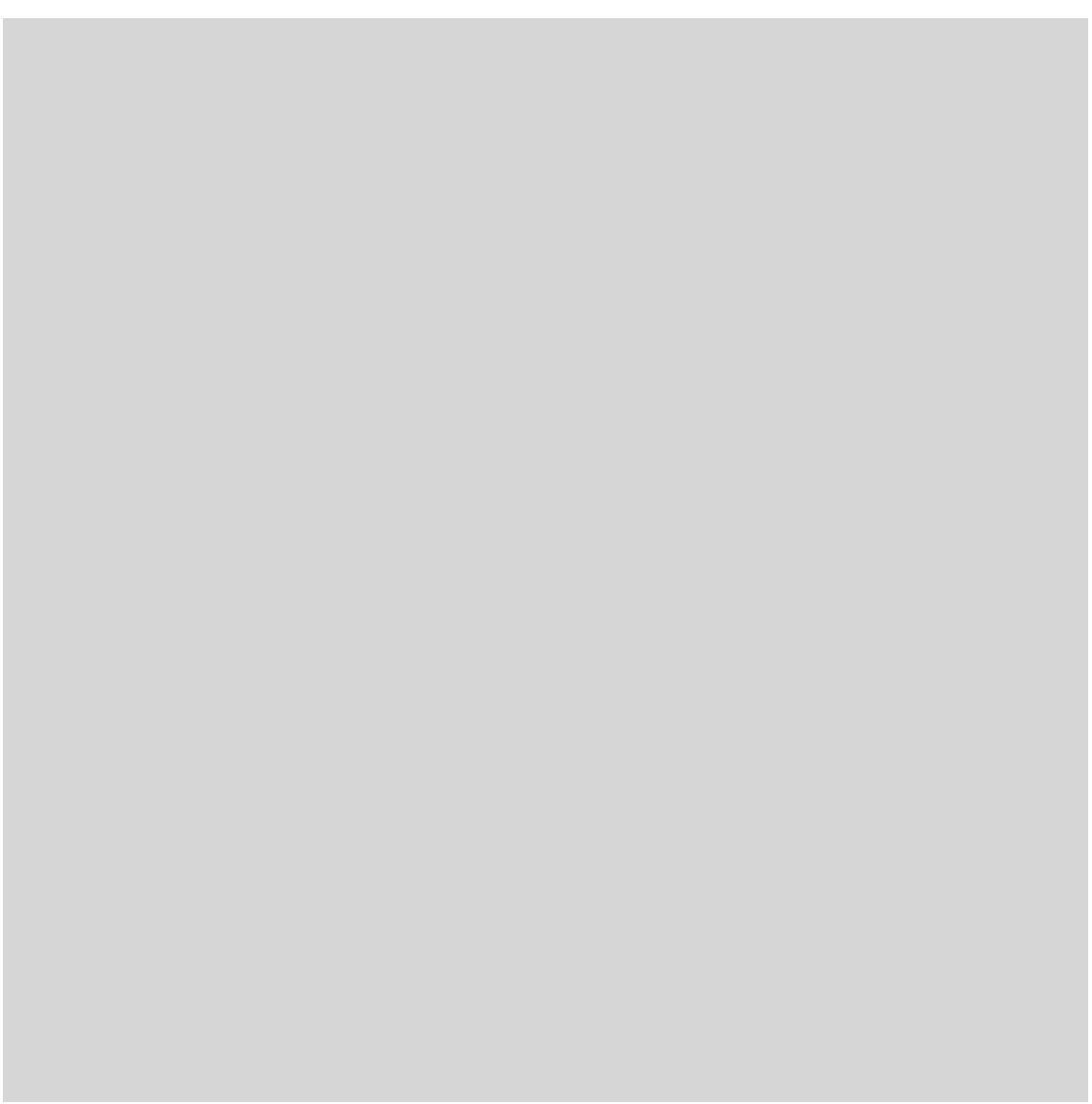

Abb. 7. Plan des Guts Jerwkant (Järvakandi) zu Beginn des 19. Jahrhunderts, auf dem die Kapelle mit einem runden Grundriss zu erkennen ist, die sich dort befunden hatte. Estnisches Historisches Archiv.

der Umgebung der Kirche schätzten, doch neben dem ständischen Stolz wünschten sie im Geist eines heranwachsenden Patriotismus ihren letzten Ruheort im heimischen Gutshof zu finden. Die Anlage eines Familienfriedhofs im Gutshofpark war sowohl eine Mode der Zeit als auch eine Herausforderung (Abb. 7).

Gestützt auf die Informationen der „Necropolis“ könnten die Herren auf Gut Noistfer (Purdi), die von Baranoffs, den ersten Friedhof in einem Gutshofpark im Jahr 1761 angelegt haben..$^{50}$ Die frühklassizistische, erhabene Kapelle, deren Wandfläche Konsolen

50 EAA, 1674-2-336, 93.

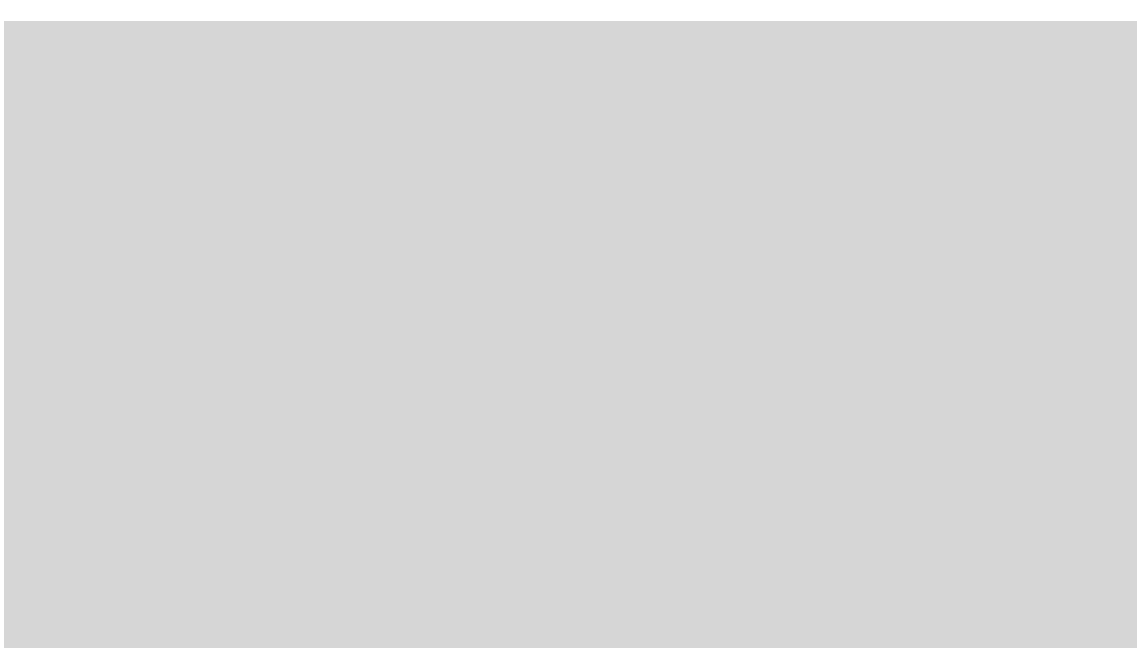

Abb. 8. Die Kapelle der Gutsherren von Noistfer (Purdi), der von Baranoffs, auf dem Familienfriedhof des Guts. 1761. Foto: Juhan Maiste.

und ein Traufengesims mit imitierten Zahnfriesen aufteilen, wurde wahrscheinlich zur selben Zeit errichtet, als auf dem Gut Bauarbeiten erfolgten. Das barock kurvige Blechdach schmückt ein kleiner Obelisk - das Trauermotiv der Aufklärungszeit (Abb. 8).

Obwohl der Anlass zur Errichtung der Kapelle die Ungeeignetheit der alten Holzkirche von Annen (Anna) als Grabstätte für den reichsten Mann Livlands gewesen sein könnte, verfügt der Friedhof eindeutig über einen privaten Charakter und eine Allee verbindet ihn mit dem Landschaftspark von Gut Noistfer.

Der livländische Literat August Wilhelm Hupel beschrieb 1791 die Besitztümer des Herren von Jerwakant (Järvakandi), Karl Friedrich von Staal, und er geizte nicht mit Lob. Der Erzieher der Prinzen von Holstein-Gottorp, Wilhelm August und Peter Friedrich Ludwig, ${ }^{51}$ Karl Friedrich von Staal, war ein in Europa weit gereister Mann und Besitzer einer unvergleichlichen Bibliothek und einer bewundernswerten Kunstsammlung, was Hupel anerkannt. Sein schönes Wohnhaus umgab ein Park im englischen Stil, was 1791 in Estland noch außergewöhnlich war angesichts der stark beschnittenen Hecken und der symmetrischen Parkgeometrie andernorts. Hupel bezeichnete das Gebäude, das auf einem Hügel das Grab verschönerte, nicht als Kapelle, sondern als mit Viires (Tallinn: Estopol, 2006), 384 . 
einem kleinen Tempel geziert. ${ }^{52}$ Später trug dieser auf der Karte des Guts dennoch den Namen Kapelle (Abb. 7). ${ }^{53}$

Das Grab im Park verursachte in der Seele eine sublime Erregung und eine Erhabenheit. Der Weg zum Grab brachte die Gedanken in eine Erregtheit, er war eine Pilgerreise zu den Plätzen des Elysiums, den paradiesischen Wiesen des ewigen Frühlings. Der englische Park wurde zum Hintergrund für die erhöhte Sentimentalität des Todes des Zeitalters der Aufklärung, die entfernteren Teile des Parks wurden den Friedhöfen zugeteilt, der Weg dorthin erzeugte eine melancholische Erregung, der weiße Tempel Erhabenheit.

Ein Gedächtnispark war auch in den Gedanken der Gutsherrin von Orrisaar, Anna Christina von Grünewaldt, präsent, als sie in den dreißiger Jahren des 19. Jahrhunderts die Nekropole Müllersfeld anlegte. Als Ort wurde das Ufer eines von einer Quelle gespeisten Sees ausgewählt, der Weg wurde von Eichen umsäumt. Laut den Erinnerungen von Otto Magnus von Grünewaldt entwarf der Maler Friedrich Ludwig von Maydell den Plan der Kapelle. ${ }^{54}$ Die Strebepfeiler aus behauenem Kalkstein des Gebäudes, das schöne Portal, der Giebelturm, die Rippengewölbe und Schlusssteine folgten der mittelalterlichen gotischen Sakralarchitektur. Die Fensterrose füllte den Raum mit dem Licht eines Mosaiks (Abb. 9). In der Kapelle war ausreichend Platz, um Erinnerungszeremonien durchzuführen, Steintafeln an den Wänden luden dazu ein, die Namen zu lesen und stimmten auf Nachdenklichkeit ein. ${ }^{55}$ In dieser Kapelle fehlt die Grabkammer, die Grabplätze befanden sich in ihrer Umgebung.

Die Gutshoffriedhöfe waren wie in Stein gemeißelte Geschichtsbücher der Familie, auf ihre Weise das Pantheon des Geschlechts. Für die Pflege

52 August Wilhelm Hupel, „Ueber die Gartenliebhaberung in Lief- und Ehstland. Diplomatische Bemerkungen aus den liefländischen Urkunden“, Die nordischen Miscellaneen (Riga: J. F.

53 EAA, 2072-4-37, 4. Auch heute finden sich an dieser Stelle die Reste einer runden Kapelle, ebenso wurde das Gut Jerwakant in den zwanziger Jahren des 19. Jahrhunderts umgebaut und die vorhandene Kapelle trägt die Jahreszahl 1848. Die Karte ist nicht genau datiert, doch sie fällt in die erste Hälfte des 19. Jahrhunderts.

54 Estnisches Historisches Museum [Eesti Ajaloomuuseum, AM], 66-1-100, 6; Im Estnischen Kunstmuseum befindet sich eine Bleistiftzeichnung mit einer ähnlichen Fensterrose wie in der Kapelle von Orrisaar (EKM j 153:976/36 G 901).

55 In dieser Kapelle, die in den dreißiger Jahren des 19. Jahrhunderts erstellt wurde, ware keine Sargkammern mehr und die Gräber befanden sich um die Kapelle herum. In dieser Zei nahm eine Tendenz den Anfang, dass in den bereits vohandenen Grabkammenn nicht meh estattet wurde, sondern stattdessen neben der Kapelle. Angaben entnommen aus: EA A, 1674 $2-336,241-247$

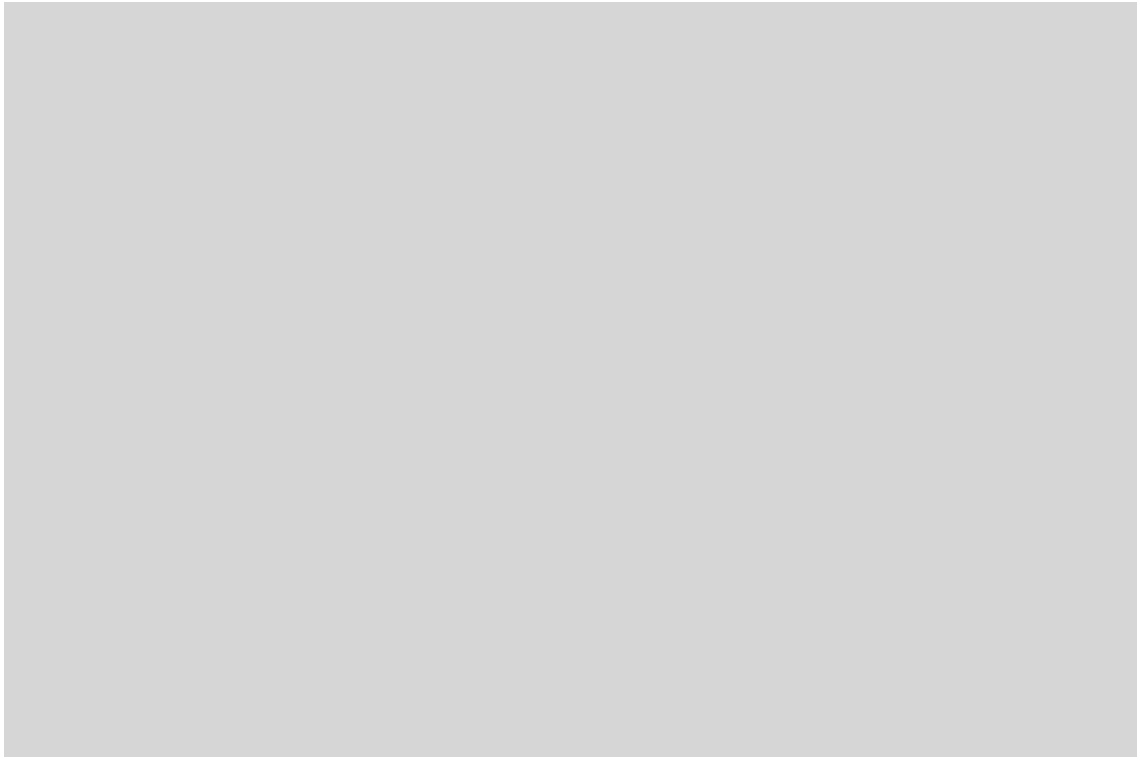

Abb. 9. Die Kapelle von Gut Orrisaar (Esna mõisa) auf dem Familienfriedhof der von Grünewaldts entwarf der Künstler Friedrich Ludwig von Maydell am Anfang der dreißige ahre des 19. Jahrhunderts. Man begann den Friedhof des Geschlechts, wo 80 Mensche bestattet sind, als Müllersfeld (Möldrivälja) zu bezeichnen. Foto: Hans Lõugas.

des Friedhofs der von Gründwaldts stellte Anna Christina aus ihrem allgemeinen Erbe 500 Rubel in Bank-Assignaten zur Verfügung und auf allen Erben lastete eine gleichmäßig aufgeteilte Verpflichtung, an der Instandhaltung teilzunehmen. ${ }^{56}$

\section{STILE UND EINFLÜSSE, ARCHITEKTEN}

Die Vorsteher der städtischen Kirchen hatten zur Vergrößerung der Einnahmen der Gemeinde private Begräbniskapellen bauen lassen, bis dies per Gesetz verboten wurde. Die Nutzung der traditionellen Formenschlüssel setzte sich auch beim Bau von gesondert stehenden Kapellen fort. So entstanden barocke, voluminöse Gebäude mit rechteckigem Grundriss, einige noch mit einem profiliert ansteigendem Traufengesims zur Stütze eines hohen,

56 Estnisches Staatsarchiv [Eesti Riigiarhiiv, ERA], T-76-1-10636. (Marta Männisalu, Esna mõisa ajalooline õiend (1983), 36.) Die Erlaubnis zur Anlage des Friedhofs wurde 1831 erbete und zum Zeitpunkt der Erstellung des Testaments 1842 war die Kapelle fertiggestellt, der die Verpflichtung zur Unterhaltung auferlegt wurde. 


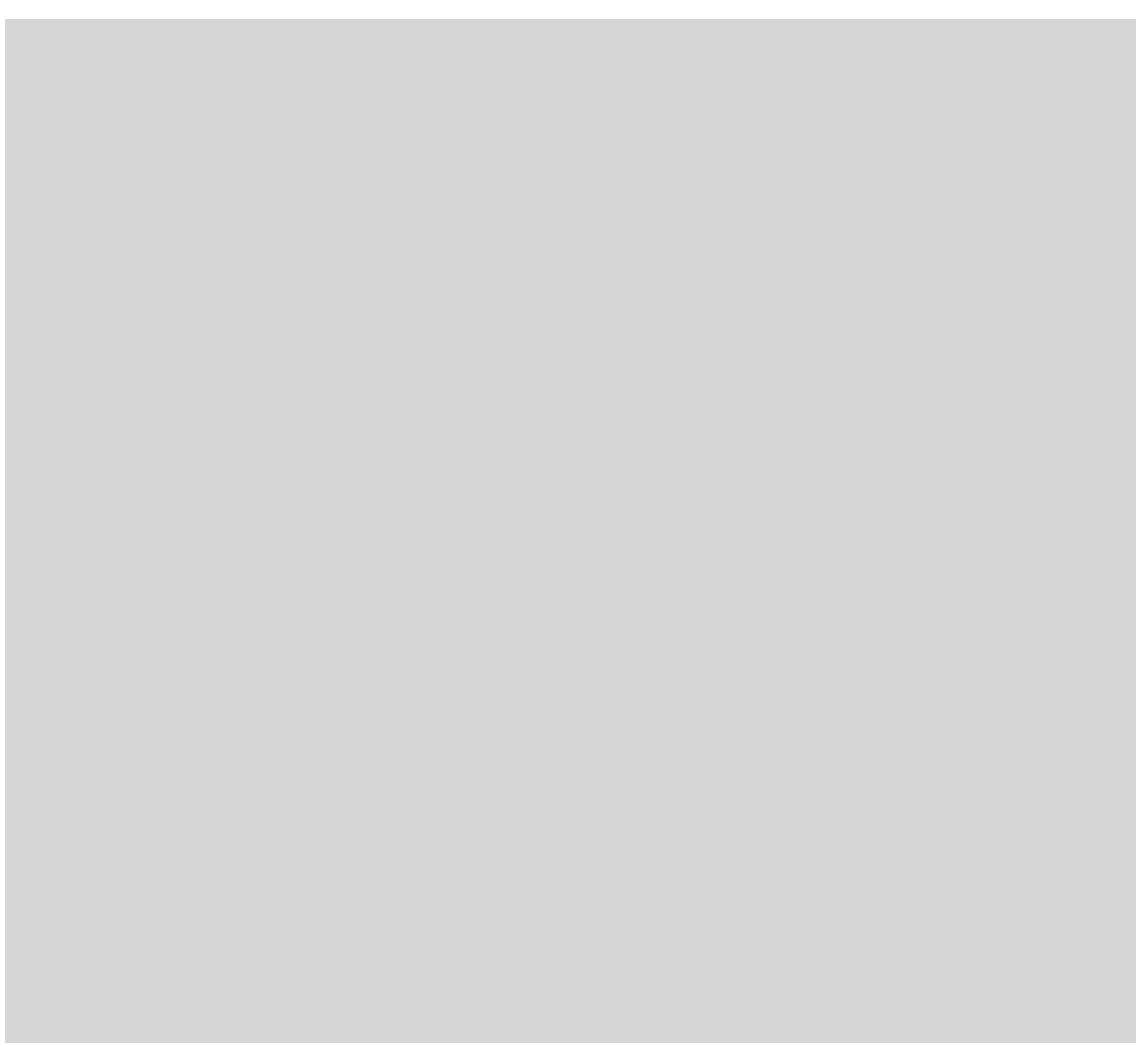

Abb. 10. Die achteckige Familienkapelle der Gutsherren von Wrangelshof (Varangu) au dem Kirchhof von Haljall (Haljala). Für die ersten Besitzer der Kapelle werden die von Focks von Gut Saggad (Sagadi) gehalten. Foto: Juhan Maiste.

anschwellenden Daches, von denen die vornehmsten mit Kupferblech oder Dachziegeln gedeckt waren. Der Akzent dieser Kapellen war eine monumentale Vorderfassade, die verschönert wurde durch ein mächtiges Portal, doch Fenster fehlten oder waren sehr klein.

Dergestalt waren die Grabkapelle von Ebba Margaretha von Stenbock (1704-1775) neben der Laurentiuskirche in Pühhalep (Pühalepa) und die des Eigentümers von Gut Neuhausen (Vastseliina), des Rittmeisters der Garde Carl von Liphart (1719-1792), in Neuhausen. Die letztere Kapelle war ein weißes Gebäude mit einfachen Pfeilern. Der hohe Turmhelm eines frühklassizistischen Tempels wird von

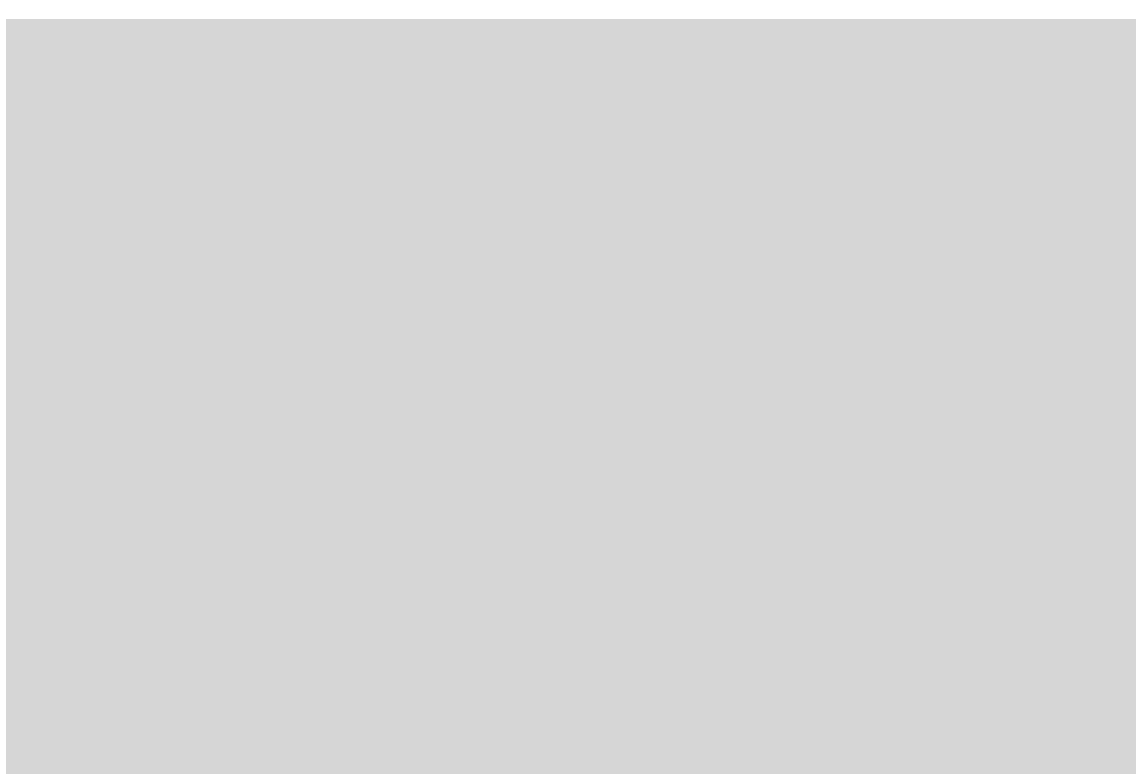

Abb. 11. Um die Rundkapelle auf Gut Haakhof (Aa) herum wurde der Friedhof doch nicht angelegt. Foto: Juhan Maiste.

einem verästelten Stern gekrönt. ${ }^{57}$ Die Tür, die in die dunkle Welt hinter dem Grab führt, ist bedeckt mit Rosetten und kurvigen Schlossschildern.

Mit der „Unabhängigkeit“ der Kapellen veränderten sich auch ihre Formen. Die persönlichen Vorlieben der Adligen schufen einen Pluralismus des Stils, doch sowohl auf dem Kirchhof als auch im Gutshofpark dominierte als Vorbild der antike griechische oder römische Tempel.

Donato Bramantes Tempietto - ein am Beginn des 16. Jahrhunderts am mutmaßlichen Hinrichtungsort des Heiligen Petrus errichteter Rundtempel - war ein Monument für den Heiligen, dem Jesus Christus die Schlüssel für das Himmelreich anvertraut hatte. In der Architektur des Tempels wurde auf die Architektur der Geburtszeit des Gottessohnes hingewiesen. Als die Franzosen die Kirche St. Genevieve zum Pantheon der nationalen großen Männer umbauten, thronte auf ihre Kuppel eine Laterne in der Form des Tempietto. 


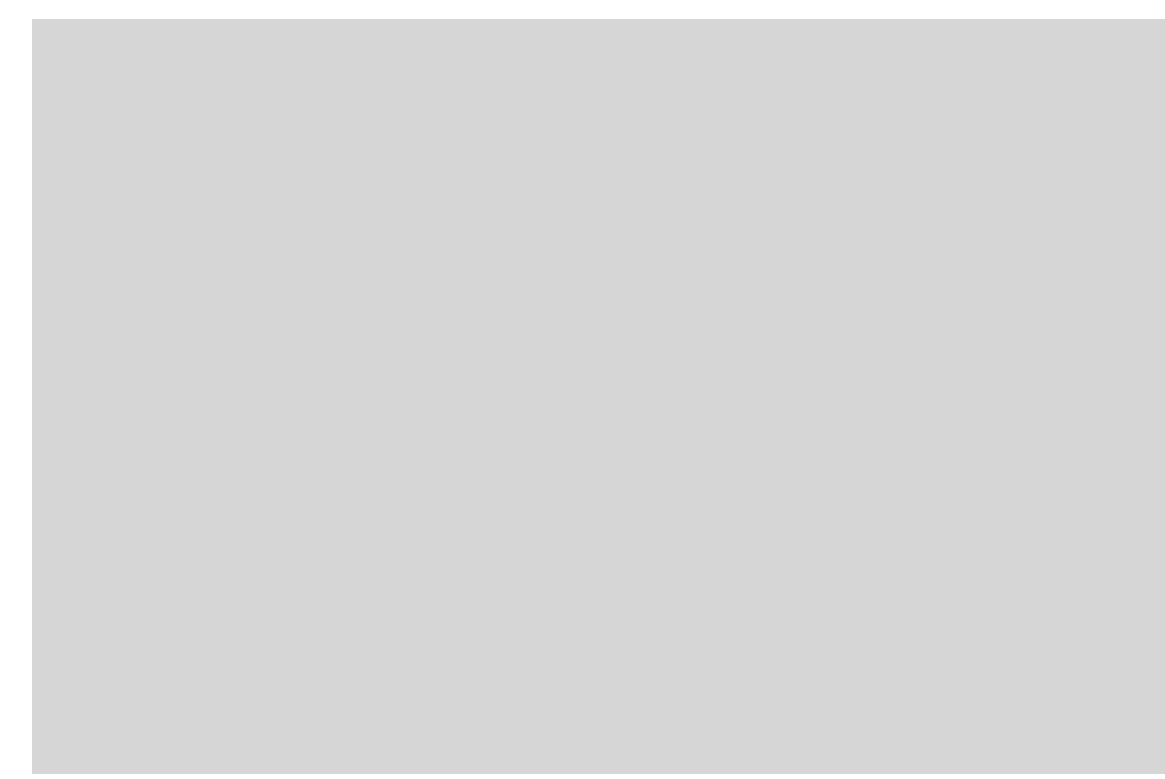

Abb. 12. Der zentrale Risalit der Kapelle derer von Aderkas, von Berg und von Buhrmeiste vereint in sich eine altgriechische Form und christliche Symbolik. 1791. Foto: Juhan Maiste.

Der Kirchhof von Haljall (Haljala) (Abb. 10), der Friedhof von Sagnitz (Sangaste) und die Wandfläche der Rundkapelle des Guts von Haakhof (Aa) (Abb. 11) sind verschönert mit Pfeilern, welche Kolonnaden nachahmen, doch dies trat auch in einfacheren Rundkapellen auf wie auf den Gütern Kaltenbrunn (Roosna-Alliku) und Jürgensberg (Kuksema), die einfache, mit einem Kuppelgewölbe versehene Rundbauten waren.

Die Form des zentralen Risalits der gemeinsamen Kapelle der Familien von Aderkas, von Berg und von Buhrmeister (1791) auf dem Friedhof von Peude (Pöide) war bereits deutlich klassizistisch (Abb. 12). Den Giebel, der die griechische Tempelarchitektur imitierenden Kapelle, schmückt das Wappen der von Anderkas, das Fries ist aufgeteilt in Triglyphen und Metopen, deren Steindekor meisterlich ist. Mit den Metopen wechseln sich mit in der Memorialarchitektur zur Klassik zählenden Memento mori ab - Schädel mit gekreuzten Beinknochen und Sonnenblumen. Obwohl dieses dekorative Ornament eine christliche Botschaft trägt - der Schädel ist ein Symbol für Adam als ersten Menschen und die von ihm begangenen Sünden und die Sonnenblume symbolisiert das ewige Leben -, entspricht dies von seiner Formsprache her eher antiken
Sarkophagplastiken. In den Nischen zwischen den Pfeilern befanden sich Skulpturen des Apostels Petrus und eines Engels mit einer Sanduhr. Gemäß der Bibel öffnet Petrus den Christen das Himmelreich: „Du bist Petrus und auf diesen Felsen baue ich meine Gemeinde, und die Pforten der Hölle gewinnen hierbei nicht. Ich übergebe Dir die Schlüssel zum Himmelreich, ..." (Mt 16:15). Der Engel mit der Sanduhr erinnert aber an den Verlauf der Zeit und die Endlichkeit des menschlichen Lebens. ${ }^{58}$

Die freistehenden Säulen des klassisch griechischen Prostylos erhoben sich hier und dort, als Bauherren fungierten die von Rehbinders auf Gut Uddrich (Udriku, 1803) ${ }^{59}$ und die von Kaulbars auf Raggafer (Rägavere) oder die von Stackelbergs auf Thomel (Tumala, 1846). ${ }^{60}$

Die von Buxhoevedens auf Ösel gestalteten zwei Kapellen am Eingang des Friedhofs von Kudjapäh (Kudjape), etwas in der Art von Propyläen (1845-1848), die direkt neben dem Tor errichtet wurden (Abb. 2, 3). Der gut zu formende Kalkstein stellte ein dankbares Material dar, nahezu wie Marmor, und er erlaubte es, Volute in ionischer Art herzustellen, Blumenblüten und erlöschende Fackeln. Hinter den Propyläen begann eine andere, heilige Welt.

Der Tempel der von Stackelbergs, Herren auf Gut Fehna (Vääna), auf dem Friedhof von Kegel (Keila) mit seinen ionischen Säulen und einer doppelten Ante stellt das stilreinste und am besten erhaltene Beispiel der klassizistischen Kapellenarchitektur in Estland dar (Abb. 13). Doch dies war gleichzeitig ein Erinnerungsort für die Entdeckungsreisen von Otto Magnus von Stackelberg zu den Ruinen des alten Griechenlands. Das meisterliche Werk erlaubt es zu vermuten, dass ein Künstler und ein Archäologe dem Baumeister Rat gaben.

Schultz, Krause und Walther sind nur einige Namen von Architekten, die mit dem Bau der Kapelle in Verbindung gebracht werden könnten. Die Kapellen der Güter Noistfer, Großenhof

58 Die Reliefs befinden sich im Museum von Saaremaa (Ösel). Petrus, Saaremaa Muuseum (Museum Saaremaa, SM), 10438:10 Ks (http://muis.ee/museaalview/308717 [letzter Zugriff am 30.07.2017]) und der Mensch mit der Sanduhr SM, $10438: 9 \mathrm{Ks}$ (http://muis.ee/museaalview/30833 [letzter Zugriff am 30.07.2017]). Eesti arhitektuur 2, Läänemaa. Saaremaa. Hiiumaa. Pärnumaa. Viljandimaa, hrsg. von Villem Raam (Tallinn: Valgus 1996), 78

59 Der Gutshoffriedhof Uddrich wurde im Jahr 1792 angelegt, doch die Kapelle stammte offenbar aus derselben Zeit wie das Herrenhaus (1803), beide sind zerstört.

60 Raggafer und Thomel liegen in Ruinen. 


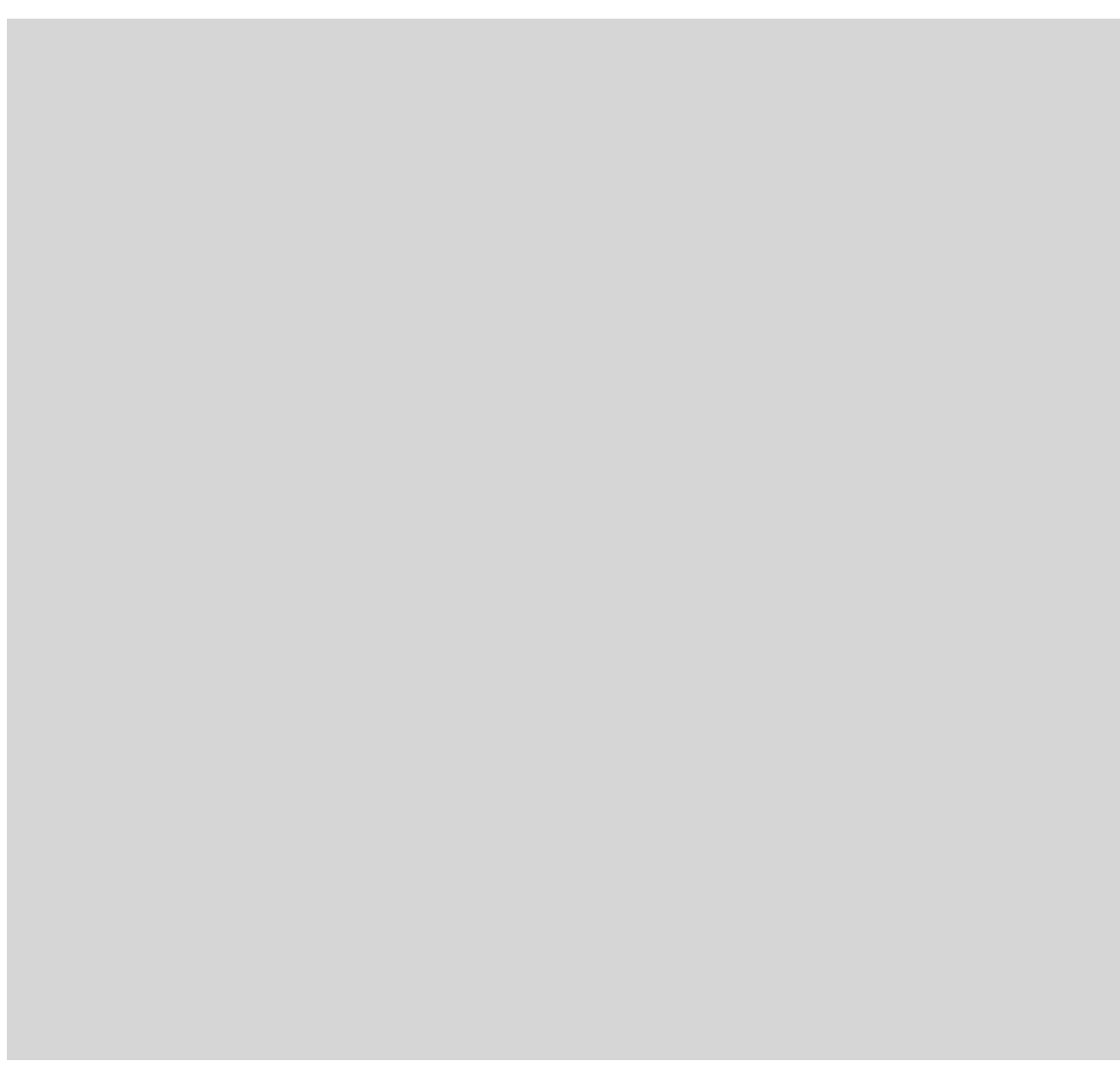

Abb. 13. Der Tempel Otto Magnus von Stackelbergs, Herren auf Gut Fehna (Vääna), au dem Friedhof von Kegel (Keila). Foto: Juhan Maiste.

(Suuremõisa) ${ }^{61}$ und Matzal (Matsalu) ${ }^{62}$ wurden in der Zeit der größten Bauarbeiten auf diesen Gütern errichtet und es kann vermutet werden, dass die Baumeister sie nach ihrem besten Gutdünken erbauten.

Eine Ausnahme bildete die Baugeschichte des Mausoleums von Fürst Michael Barclay de Tolly (Abb. 14). Die Familienkapelle des Fürsten wurde am Lieblingsort des Heerführers angelegt, auf Gut Berckhof, wo er den Blick auf die eiszeitliche Flusssenke des Kleinen Embach (Väike Emajõgi) genoß, doch diese wurde von einer Lehrkraft der St. Petersburger Akademie, dem Architekten Apollon Ščedrin entworfen. Autor des Monuments war der Professor der St.

61 Die Kapelle von Ebba Margaretha von Stenbock bei der Kirche von Pühhalep.

62 Die Kapelle der Manderstierns bei der Kirche von Karusen (Karuse).

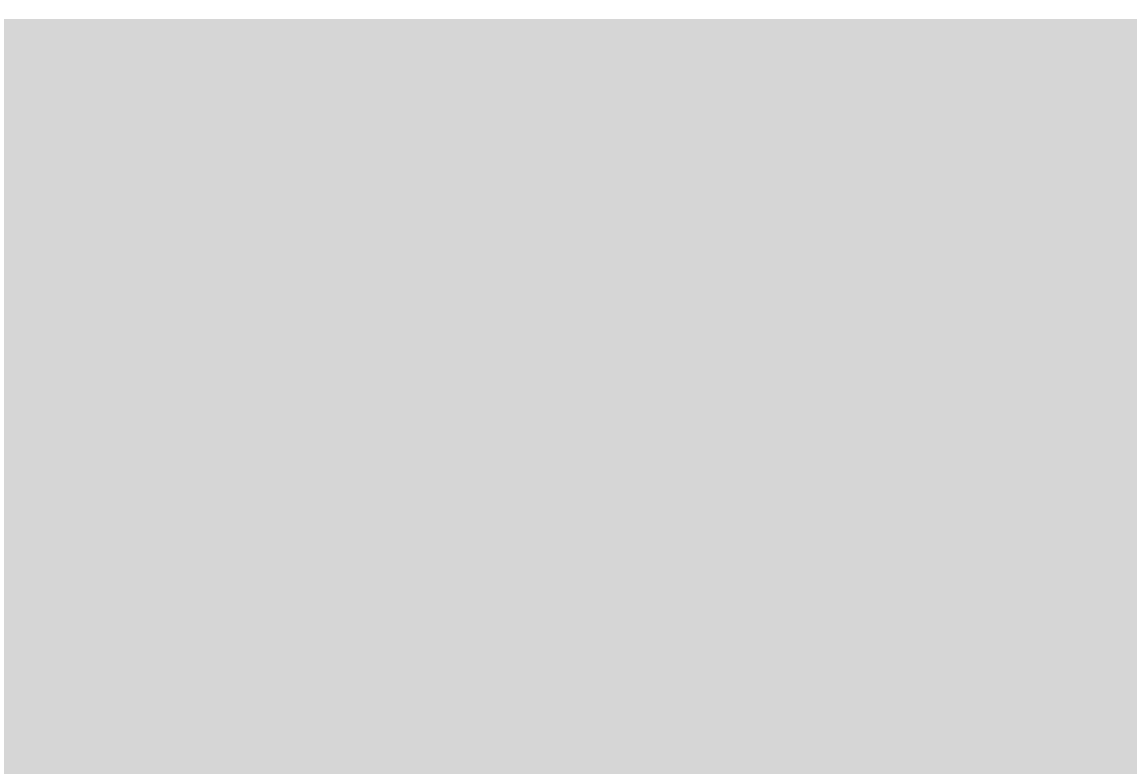

Abb. 14. Apollon Ščedrin. Die Familienkapelle von Fürst Michael Barclay de Tolly au Gut Beckhof (Jõgeveste). 1823. Foto: Juhan Maiste.

Petersburger Akademie der Künste, Vasilij Demuth-Malinovskij, ${ }^{63}$ für dessen Anerkennung in Russland spricht seine Teilnahme an der Schöpfung des Triumphbogens auf dem Palastplatz in St. Petersburg und an derjenigen der Skulpturen des zur Erinnerung an die Eroberung von Paris errichteten Narva-Triumphbogens.

Die Dienste des Fürsten für das russische Kaiserreich und seine Nähe zum Zaren eröffnet die Beileidsadresse Alexanders I. an die Witwe des Marschalls: „Der Staat verlor einen seiner eifrigsten Diener, die Armee einen Feldherren, der ihr beständig mit seiner Tapferkeit ein Vorbild war, und ich einen Waffenbruder, dessen Treue und Hingabe mir stets wertvoll war." Der Zar wünschte ein feierliches, staatliches Begräbnis in der St. Petersburger Kazaner Kathedrale, dort wo bereits Generalfeldmarschall Michail Kutuzov ruhte, doch die Fürstin Helene Auguste war kategorisch dagegen und setzte ihren Willen schließlich durch. ${ }^{64}$

63 Helmi Üprus, Barclay de Tolly mausoleum (Tallinn: Eesti Riiklik Kirjastus, 1957), 8. 64 Rein Helme, Kindralfeldmarssal Barclay de Tolly (Tallinn: Eesti Entsüklopeediakirjastus 2006), 386. 
Die architektonische Idee der Kapelle de Tollys drückte sich in einer Innovation aus, das Mausoleum war keine Kopie eines bestehenden Bauwerks, sondern das Ziel bestand darin, den Eindruck eines Triumphbogens zu erwecken, wie sie für die Kaiser im alten Rom erbaut worden waren. Den Lünettebogen rahmen Sträuße von Eichen-, Palmen- und Ölbaumästen und sie vertiefen den Eindruck noch. Im heidnischen Rom markierte das an der Spitze der stufenförmigen Attika angebrachte Kreuz ein Mausoleum. ${ }^{65}$ Römische Motive wiederholen sich auch auf dem Denkmal, selbst die Kleidung des Heerführers imitierte ein Brustportrait des römischen Kaisers Hadrian.

Die unter verschiedenen politischen Regimen unter staatlichem Schutz stehende Kapelle ist komplett erhalten - es handelt sich um das Denkmal und das Kellergeschoss mit den Sarkophagen des Fürsten und seiner Gattin. Der auf einem architektonischen Sockel befindliche Obelisk bildet den Hintergrund für eine Bronzebüste des Heerführers und zwei weibliche Figuren in antiker Kleidung (Abb. 15). Die Verteidigerin der Zivilisationen, Minerva, steht vor einem Trophäenstrauß der Napoleonischen Kriege, die zweite Figur trauert vor einer Aschenurne und ist eine Allegorie Russlands, was aus dem Wappen des russischen Zarenreichs vor ihren Beinen gefolgert werden kann. Die Büste des Feldherrens befindet sich auf einem Postament aus Marmor, auf dessen Fuß finden sich die vergoldeten Attribute eines Helden - ein Kürassierhelm, die Fürstenkrone und Orden. Auf dem Sockel des Obelisken ist ein Bronzerelief: Der Einmarsch der russischen Truppen im Jahr 1814 in Paris erfolgte unter der erfolgreichen Führung von Feldmarschall Barclay de Tolly und stellte für Russland einen Triumph in den Kriegen gegen Napoleon dar. ${ }^{66}$ Die Lebensgeschichte des Heerführers wird noch auf kleinen Metallplatten neben dem Denkmal beschrieben. Für das Monument wurden edle Materialien genutzt - Granit, Marmor, Porphyr, Bronze und Vergoldungen.

In der Architektur der Kapelle der von Mensenkampffs in Tarwast (1825) wurde eine Pyramide vereinigt mit palladioartigen, sich nach vier Richtungen öffnenden Portiken (Abb. 16). Von seiner Gestaltung folgt dies der Sepulkralarchitektur der französischen Architekten in St. Petersburg war.

66 Helme, Kindralfeldmarssal Barclay de Tolly, 386

Abb. 15. Vasilij Demuth-Malinovskij. Monument Barclay de Tollys im Mausoleum von Gut Beckhof (Jõgeveste). 1823. Foto: Juhan Maiste. 


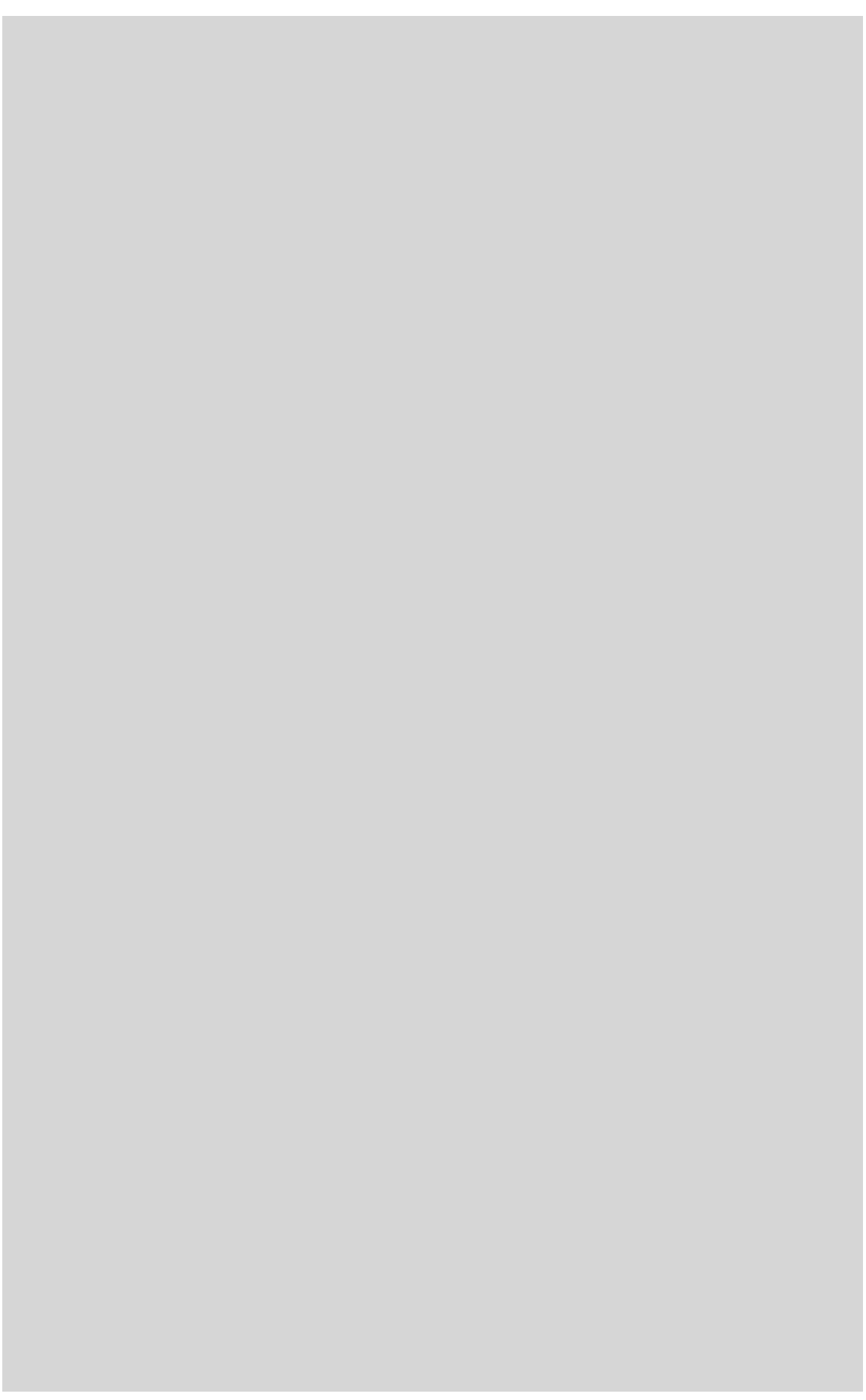

Abb. 16. Die Familienkapelle der von Mensenkampffs auf Gut Tarwast (Tarvastu). 1825 Foto: Reet Pius.

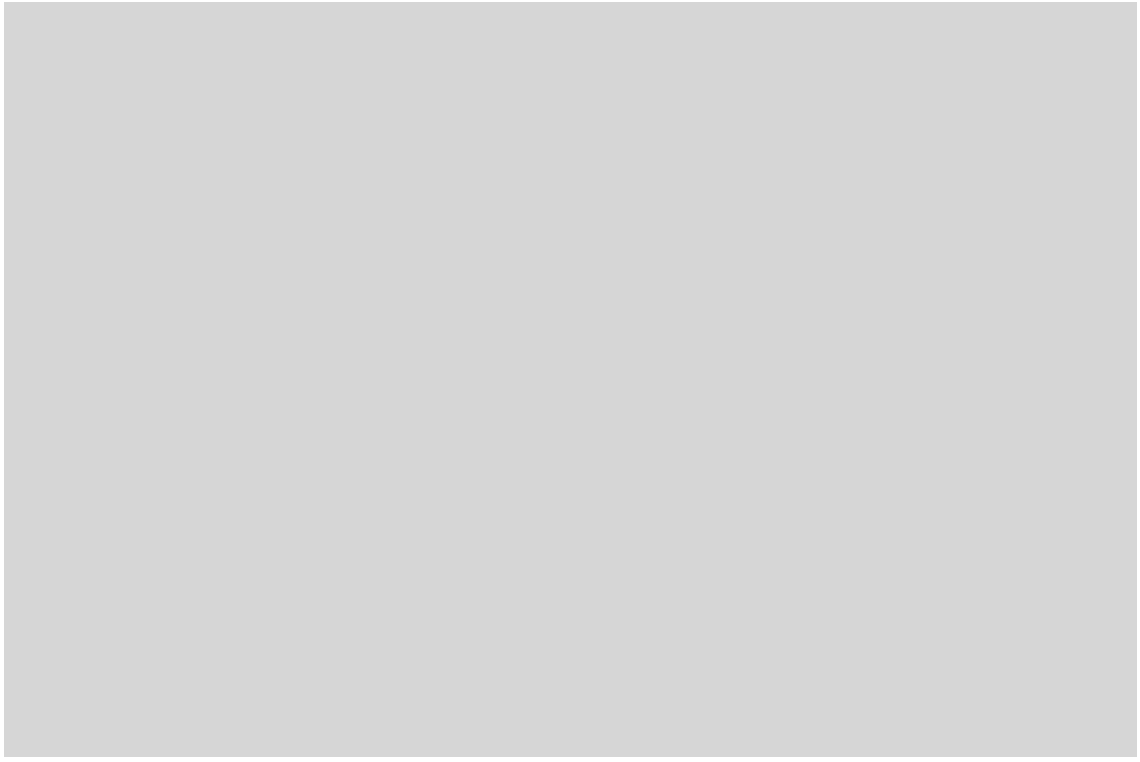

Abb. 17. Johann Wilhelm Krause. Pyramide. Fassade. Nach Friedrich Gilly. Aus dem Jahr 1814. Aus der Sammlung der Universitätsbibliotek Tartu.

Nicholas-Henri Jardin und Etienne-Louis Boullée, doch im deutschen kulturellen Bewusstsein traf man auf diese Idee im Jahr 1791 durch Friedrich Gilly. ${ }^{67}$ Woher erhielt Charlotte Luise von Mensenkampff die Anregung zur Anlage dieses außergewöhnlichen Monuments für ihren Gatten, der in dieser Kapelle auch als einziger bestattet ist? Wahrscheinlich machte sie Johann Wilhelm Krause damit bekannt, der von Gilly angeregt worden war und dessen Arbeiten kopiert hatte (Abb. 17). Das Thema geriet mit der Diskussion um eine Gedächtnispyramide für Martin Luther in Deutschland auf die Tagesordnung. ${ }^{68}$

Die visionären Ideen der europäischen Architektur erreichten die Landschaft Livlands in einer durch die örtlichen Architekten umgearbeiteten Form. Die Kapellenarchitektur war wie ein Spiel, wie eine Möglichkeit sich ein Miniatur-Europa zu erschaffen und sich bedeutende Gebäude in seinen Hof zu holen.

67 Maiste, ,J. W. Krause ja ajastu arhitektuuripilt“, 55. Friedrich Gilly (1772-1800) war ein junges deutsches Architekturgenie.

68 Zur Beziehung Johann Wilhelm Krauses zum Schaffen Friedrich Gillys siehe Maiste, ,J. W. Krause ja ajastu arhitektuuripilt"“, 36-37, 50.; Bibliothek der Universität Tartu [Tartu Ülikooli raamatukogu, TÜR], 9-1-21, 4-5. 


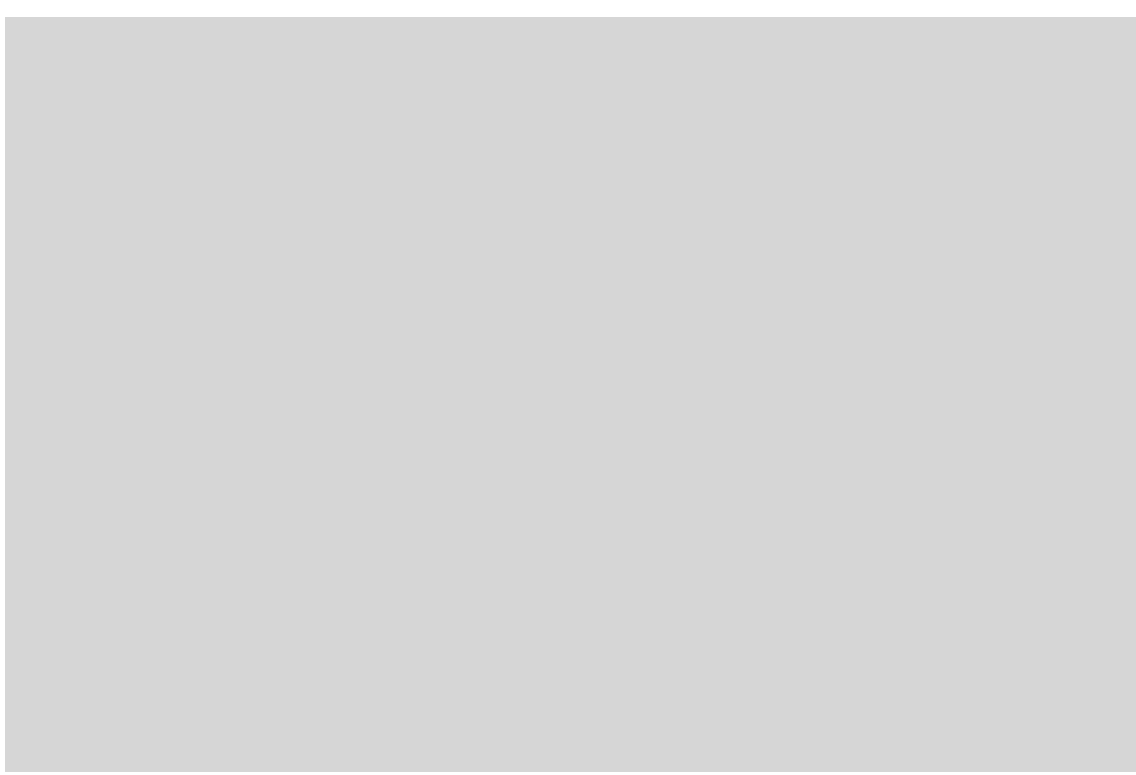

Abb. 18. Die Familienkapelle der von Dellingshausens von Gut Kattentack (Aaspere) im Dorf Kasperwiek (Käsmu). Foto: Juhan Maiste.

Es kann vermutet werden, dass auf Anregung von Krause noch so manches Mausoleum errichtet wurde, denn eines seiner Lieblingsmotive bestand in einer Rotunde in einem Hain oder auf einem Hügelhang. Grabrotunden wiederholen sich auch bei seinen Entwürfen für Kapellen. ${ }^{69}$ Urheber der in Rosenplänters Handbuch als Beispiel angeführten Entwürfe von vier Kapellen sowie der ihren Bau vereinfachenden Quer- und Durchschnitte sowie der Erklärungen war kein anderer als Krause selbst. ${ }^{70}$

Eine in der zu untersuchenden Periode beginnende Erscheinung war die Nutzung von Feldsteinen in der Kapellenarchitektur, der die aus weißem Kalkstein gefertigte Eckenrustika in der Kapelle der von Dellingshausens in Kasperwiek (Käsmu) (Abb. 18) oder die verputzten Konsolen in der Kapelle der von Anreps auf Kerstenhof Feierlichkeit hinzufügten. Der Gebrauch des Baumaterials von Wirtschaftsgebäuden als Schmuck bei einem nach Majestät strebenden Mausoleum belegt eine wertschätzende

69 Polli, „Sentiment ja ratio: hauamonumendid“, 296.

70 Ibidem, 294.
Beziehung gegenüber der Vergangenheit der eigenen Volksgruppe. Feldsteine als Baumaterial der alten Ordensburgen stellten im deutschbaltischen Kulturraum ein ebenso archetypisches Material dar wie Marmor im alten Rom.

Begräbniskapellen waren gleichzeitig sowohl ständischrepräsentative als auch familiär intime Monumente in der Landschaft. In ihnen eröffnete sich die Gefühlswelt der Gutsherren und die Einstellungen. Die anfangs unter dem Druck des Gesetzgebers errichteten Begräbniskapellen verloren in der Mitte des 19 Jahrhunderts ihre praktische Bedeutung als Ort der Bestattung von Verstorbenen. Das Umdenken bezüglich von Leben und Tod sowie neue Verständnisse von Hygiene führten zum Zumauern von Grabkammern und auch die hochwohlgeborenen Toten bestattete man ebenso wie die einfachen Sterblichen in der Erde. Die Kapelle auf dem Friedhof verfügte über eine Bedeutung als eine meditative und angenehme Umwelt, wo man nach den Worten Pastor Rosenplänters Trost erhielt, über Leben und Tod nachdachte und Zeit in Gesellschaft mit lebensgeschichtlichen Notizen, Sentenzen und Gedenktafeln verbrachte. $^{71}$

Reet Pius: Family Chapels in Churchyards and Manor Cemeteries

Keywords: Cemetery Reform of Catherine the Great; cemetery architecture; cemetery park; Chapels; Baltic German family manors; family cemetery; Barclay De Tolly; Enlightenment; Jacques Delille; Christian Cajus Lorentz Hirschfeld; August Wilhelm Hupel

\section{SUMMARY}

The 1772 cemetery reform of Catherine the Great, Empress of Russia, resulted in great changes in the cemetery culture of Russia's Baltic provinces. The ban on burials in churches and the vicinity of churches resulted in the rapid development of cemetery parks outside of

71 Rosenplänter, Ueber Kirchhöfe und Beerdigung der Todten, 79. 
settlements. The strong political relations of Estonia's manor owners with the Russian central government resulted in the nobles being given the privilege to establish burial plots in the churchyards, but in Livonia, this was strictly prohibited. Simultaneously with the parish cemeteries, the owners of private manors established family cemeteries on their manors. The new cemeteries were not only places to bury the dead, but, inspired by contemporary poets, they were seen as family altars, which were visited regularly and which was accessed by path that was attuned to contemplation.

The cemetery is complex, which includes a garden, chapel and allée, and if possible, a body of water. Noble trees were planted along the path leading to the cemetery. Oaks were preferred, which due their mighty shape were considered to be the symbol of family and nobility. Influenced by the poetry of the Enlightenment, evergreens - silver firs, thuja trees, and spruces - were called "sad trees". The French poet Jacques Delille, whose works were popular among the Baltic Germans, sees women as mourners. And many family cemeteries were established at the initiative of women. Examples of Ancient Greek architecture, in the form of temples with porticos or antas, or the small-scale copies of the Pantheon from Ancient Rome, dominated in cemetery architecture. The chapel was comprised of underground burial chambers and aboveground memorials. A so-called memorial altar was located in the end wall of the chapel, which have survived until the present day in a few places. The Barclay de Tolly monument is the most majestic in Estonia.

Already in the 1830s, the family chapels became memorials and burials no longer took place there. However, chapels continued to be built until in Estonia until the early $20^{\text {th }}$ century.

\section{CV}

Reet Pius (until 2012 Rast, b. 1964) is a PhD student at the University of Tartu. Her current research subject is the Lutheran sacral art of the Enlightenment in Estonia and Livonia. Previously, she dealt with the church art of the Early Modern period. From 1987 to 1995, was the head of the Painting and Polychromy Department at the Kanut Restoration Centre; from 1995 to 2009, the Coordinator of Research Work at the Art Museum of Estonia. Co-author of History of Estonian Art 2 (2005) with the theme "Altarpiece - Lord's Table and object of prestige. Altar Art in Estonia during the Early Modern Period." 